\title{
Describing astronomy identity of upper primary and middle school students through structural equation modeling
}

\author{
Arturo Colantonio $\odot,{ }^{1,2}$ Irene Marzoli $\odot,{ }^{1}$ Emanuella Puddu, ${ }^{2}$ Sandro Bardelli $\odot,{ }^{3}$ \\ Maria Teresa Fulco, ${ }^{2}$ Silvia Galano, ${ }^{4}$ Luciano Terranegra, ${ }^{2}$ and Italo Testa ${ }^{2,4, *}$ \\ ${ }^{1}$ School of Science and Technology, Physics Division, University of Camerino, 62032 Camerino, Italy \\ ${ }^{2}$ INAF-Astronomical Observatory of Capodimonte, 80131 Naples, Italy \\ ${ }^{3}$ INAF-Osservatorio di Astrofisica e Scienza dello Spazio, 40129 Bologna, Italy \\ ${ }^{4}$ Department of Physics, University Federico II, 80126 Naples, Italy
}

(Received 31 August 2020; accepted 15 April 2021; published 28 May 2021)

\begin{abstract}
We describe how young students situate themselves with respect to astronomy through an identity framework that features four dimensions: interest, utility value, confidence, and conceptual knowledge. Overall, about 900 Italian students, from 5th to 9th grade (9-14 years old), were involved in the study. We tested our model using confirmatory factor analysis and structural equation modeling. Differences between girls and boys and across school levels were also investigated. Results show that interest has both a direct and an indirect effect on astronomy identity. The indirect effect of interest on identity is mediated by utility value. Moreover, confidence mediates the effect of interest on conceptual knowledge. Concerning differences between girls and boys, we found that the effect of interest on identity is greater for girls than for boys and that the utility value mediates the effect of interest on identity for boys but not for girls. Finally, our findings show also that the students' interest in astronomy and confidence in their performance decrease with age, with a potential negative impact on conceptual knowledge and future career choice in astronomy. The astronomy identity framework can be employed to examine the role of affective variables on performance and persistence in astronomy and to improve the design of teaching-learning activities that can potentially stimulate a lasting interest in astronomy.
\end{abstract}

DOI: 10.1103/PhysRevPhysEducRes.17.010139

\section{INTRODUCTION}

How do student interest and attitude towards astronomy change over time and, eventually, lead to pursue a career in such a field? To address this issue, one needs a more complete picture about the factors underlying students' future aspirations in astronomy. However, most of the work in astronomy education research has historically concerned students' conceptual knowledge about a variety of topics: from day-night cycle and familiar phenomena, such as seasonal changes and Moon phases [1-11], to more advanced topics, such as light spectra, stars, and cosmology [12-16]. Far less effort has been devoted, so far, to research into attitudes towards astronomy [17-21]. Actually, the investigations in science education research about attitudes have led to an understanding of the main motivations (e.g., enjoyment, good grades, career opportunities, a good teacher, etc.) underlying the choice of a science-technology-engineering-mathematics (STEM)

*italo.testa@unina.it

Published by the American Physical Society under the terms of the Creative Commons Attribution 4.0 International license. Further distribution of this work must maintain attribution to the author(s) and the published article's title, journal citation, and DOI. field at the undergraduate level [22-25]. Furthermore, to study the role of affective variables can provide us with fruitful insights into how to address the gender gap in astronomy careers [26]. For instance, in a recent study with physics undergraduates [27] the authors found that for women, higher perceptions of psychological well being and engagement are associated with higher identification with physics.

The present study aims at filling this gap in literature by focusing on the relationships between affective, cognitive, and metacognitive constructs to describe how upper primary and middle school students (9-14 years old) situate themselves with regard to astronomy and, in particular, to a potential career in astronomy. We will call this framework astronomy career identity or, put more simply, astronomy identity. Within this framework, we also aim at explaining how students' personal connections to astronomy change over time as they progress through school levels. The reason for introducing an identity framework that is specific to astronomy for the targeted age range is threefold. First, research has proved that low perceived academic competence in science leads to a decreased science identity [28]. Thus, since students at the elementary and middle school level often hold numerous alternative conceptions about basic astronomy phenomena [29], it would be interesting to 
look whether conceptual knowledge is related to identity, specifically in the astronomy field. Second, reviews about interest, motivation, and attitude towards science and technology consistently show that from the last years of primary school through middle school, students begin to see science as less relevant [30]. Therefore, given that astronomy is prevalently taught at these school levels and is considered as intrinsically motivating for students and far more exciting than other scientific disciplines [17], it would be interesting to investigate if such decrease of interest also holds for astronomy and whether it affects the choice of a future career in the field. Third, educational theories, such as expectancy value and identity-based motivation [31,32], predict that students' motivation towards a career field (e.g., physics) decreases with experienced difficulty if difficulty is perceived as something that impedes attaining the career-related identity, while it increases if the utility value in engaging in an activity is acknowledged as relevant to achieve a certain aim. For this reason, it is worthy to investigate how confidence and utility value contribute to build the astronomy identity. In Sec. II we review prior work about STEM identity and, in particular, physics identity [33,34] given the closeness of the two fields. Then, we will describe the four domains that we hypothesize can play an important role in the astronomy identity framework: interest, utility value, confidence, and conceptual knowledge.

\section{THEORETICAL FRAMEWORK}

\section{A. STEM identity}

In general, the identity construct indicates a person's understanding of the self and of the others in a social context in which the self is placed [35]. The construct can be extended to the understanding of how a person relates to a discipline [36] and to the professionals working in that discipline [37,38]. As far as the STEM field, literature has proposed several conceptualizations of identity from different theoretical perspectives $[27,39,40]$. Among these conceptualizations, three have received significant attention: (i) identity as a sense of community [33]; (ii) identity as constituted by extrinsic and intrinsic attitudes [41]; (iii) identity as a match between science learned at school and real science [42]. Regardless of the adopted theoretical perspective, it emerges that STEM identity is strongly connected to attitudinal constructs like fascination, value, and competency beliefs [34,43-47]. Moreover, studies in STEM education consistently show that persistence and performance success at the university level are linked to a strong identification with a discipline [48-50]. Conversely, difficulties encountered when entering STEM academic courses may hamper the maintenance of a durable science identity [51]. For instance, Robinson and colleagues $[28,40]$ found three types of STEM identity trajectories at the college level: (i) high or stable students, who consistently reported high identity through a semester; (ii) moderate or slightly increasing students, characterized by a moderate initial identity that slightly increased through the semester; (iii) moderate and declining students, characterized by a rapid decline in their STEM identity. The high or stable students reported significantly higher exam scores in comparison to the other two groups. Similarly, Chemers et al. [37] found that the identity as a scientist, measured by items such as "In general, being a scientist is an important part of my self-image," predicts the commitment to a science career, measured by items such as "I intend to work in a field of scientific research." For younger age groups-middle school and early highschool-the science identity construct is psychometrically distinct from the attitudinal measures. In particular, at that age, perceived personal science identity and perceived recognized science identity form a unique identity construct [46]. Within this framework, studies found that hands-on activities increased middle school students' desire to become a STEM professional [52] or that engaging underrepresented students in practices that resemble STEM experts' work promoted their STEM identities in terms of agency in science and recognition by others [43,47]. Recent studies suggest that, similarly to college students, also younger students with a high perception of their own ability seem to have a more stable STEM identity, while students, who report a low sense of ability, struggle to maintain their motivation toward STEM [53]. Overall, STEM identity construct has been thoroughly used to study why girls are less attracted by STEM careers and to address the problem of girls' drop-out in STEM disciplines. Ivie and colleagues [54] identified three factors of possible attrition from a career in the astronomy research: (i) the imposter syndrome, (ii) the role of mentoring, (iii) family and relationship situations. Imposter syndrome is defined as the belief that success is not due to one's own ability but to having manipulated others' perceptions of the self [55]. In other words, personal success is attributed to factors beyond individual control, while others' success is attributed to competence. The low quality of the working relationship with advisors is considered another factor that increases women's will to leave a certain career path. The third factor, found by Ivie and colleagues in their study, is the so-called two-body problem: namely, the difficulty for academic couples to find an employment in the same geographic area, with the result that it is often the woman who is compelled to give up her career aspirations. Among these three factors, only imposter syndrome could be relevant for our study. However, we found no studies that provide evidence for the existence of imposter syndrome among primary and middle school students. In the study by Ivie et al. [54], gender had no direct effect on attrition, but, rather, its effect was mediated by the three above factors. Other studies investigated the association between gender and STEM career identity. A pervasive result in STEM literature is that 
young female students may not identify themselves with STEM disciplines because of their perception of these areas as predominantly masculine [56-63]. Conversely, girls can implicitly prefer to undertake careers where the percentage of girls is perceived as higher [64]. From these results, it seems clear that a relevant role in the girls' lack of identification with STEM disciplines is played by gender stereotypes [65-71]. Gender stereotypes are conceptualized as socially shared representations of categorization, interpretation, processing, and decoding of sexual reality [72]. In other words, gender stereotypes form a coherent system of beliefs and conceptions about boy and girl identities and, once adopted, seem to play a key role in career choices $[58,68,73]$. To this regard, Cundiff and colleagues [74] found that stronger gender stereotypes in women were associated with lower STEM career identity and, conversely, stronger gender stereotypes among men were associated with higher STEM career identity. Consistently with previous work, a French study found that female engineering students had fewer gender stereotypes than their female colleagues in the humanities field [65]. Effects of gender stereotypes can be canceled out or limited with suitable approaches. For instance, in a study with undergraduate engineering and chemistry students, when female students were taught by female science professors, the latter were recognized as role models to identify with, thus reducing the implicit stereotype that science is masculine [75]. Among the disciplinary areas for which it is possible that students develop a STEM identity, the construct of physics identity is the most relevant for this study. More precisely, research suggests that physics identity is related to interest, confidence in preparation, self-efficacy, perceived utility value of the discipline, and sense of belonging to the community [76,77]. In their research studies, Hazari and colleagues [34] found a significant relationship between high school students' physics identity and physics career choices. The authors also found a number of relevant factors for the development of a sound physics identity for girls, including teacher encouragement and explicit discussion of underrepresentation of women in scientific fields. Other studies have shown a link between physics identity and performance in introductory physics courses [78] and between identification with physics as a discipline and higher levels of psychological well-being over time [27]. A recent cultural study [79] reports the case of two women initially enrolled in astrophysics doctoral studies, who later repositioned themselves outside a research path. The author frames the analysis of the work trajectories with two dominant cultural models for astrophysics: the culture of competence and that of the stereotypical astrophysicist. An important role in shaping the work identity in astrophysics is also played by the resources of the community of astrophysics research, such as meetings, seminars or collaborations between different groups. The results show that the two female students' experiences often did not completely fit into these models, which at some point interfered with their trajectories into astrophysics careers.
Finally, female students' identification with STEM disciplines may be hampered by sexism experienced during science classes. Sexism, whether real or perceived, is constituted by discriminating acts that happen due to a person's gender and it is thought to be one of the main reasons for women's underrepresentation in physics and astronomy [80]. Sexism can also be traced in microaggressive messages that reinforce gender stereotypes and that are delivered, explicitly or implicitly, by means of language or behavior. However, research about sexism in primary and secondary school educational levels is still underdeveloped. For instance, in Italy, where gender stereotypes are prominent [81], a study about microaggressions at the university level [82] shows that microaggressions impacted student social integration within the campus community and that microaggressions indirectly contributed to a negative perception of campus climate. The study, however, does not address the relationships between microaggression and interest in the field or academic performances in specific disciplines.

As an exploratory study, in the present article, we will not delve into the relationships between gender stereotypes and astronomy identity, limiting our attention to affective variables. In particular, in the following, we will review in more detail four factors that, among the ones suggested by the above reviewed literature, we hypothesize as most relevant for our conceptualization of astronomy identity; namely, interest in the subject area, utility value, competency belief (confidence), and conceptual knowledge.

\section{B. Interest}

Among the affective variables used in prior works about STEM identity, interest plays a key role in explaining students' persistence in science. In early studies, interest refers to the "preference to engage in some types of activities rather than others" [83]. As such, prior work in science education has shown that interest has a positive effect on career choices at undergraduate levels [30,84-86], on academic achievements [87], and conceptual change [88-90]. More recently, Renninger [91] conceptualized interest as "both a psychological state and a predisposition to re-engage content over time" (p. 106). In this developmental model [92] interest can be categorized into situational or individual interest. Situational interest is an external form of motivation, which can be elicited by a specific situation that stimulates short-term, focused attention. Individual interest is a more autonomous form of motivation that involves an individual's long-term engagement in an activity or content. Such categorization is somehow similar to the threefold model for interest in physics proposed by Haussler and colleagues [93]: (i) interest in a particular topic; (ii) interest in a particular context; (iii) interest in a particular activity. Concerning prior works in astronomy education, earlier studies focused more on students' general attitudes toward astronomy. For instance, 
Zeilik and colleagues [94] developed a 22-item survey (Attitudes Toward Astronomy, ATA) to measure the impact of an innovative astronomy course at the university level. The survey featured four scales: affect ("I will like astronomy"), self-efficacy ("I can learn astronomy"), perceived value ("Astronomy is worthless"), and perceived difficulty ("Astronomy is a complicated subject"). While the ATA survey has been frequently used in subsequent studies about students' and teachers' attitudes towards astronomy [95-97], it is worth noting that the ATA does not feature specific items about students' interest toward astronomy. Other studies surveyed students' level of interest towards (i) astronomy in general [17]; (ii) more specific topics, for instance, star properties and stellar evolution [98]; (iii) related topics such as extraterrestrial life, UFOs, and living in space [99]. A further study investigated gender differences in the interest about various astronomy contexts [100]. Results show that girls were significantly more interested than boys in topics such as the possibility of extraterrestrial life, stars, planets and the universe, why the stars twinkle and the sky is blue, whereas boys were significantly more interested in technologyrelated contexts, such as rockets, satellites, and space travel, Moon landing, and satellite communications. We found only two studies that developed specific scales to measure interest as conceptualized in psychology education. Marusic and Hadzibegovic [19] used a multidimensional instrument to compare 16-18 year-old students' attitudes in astronomy in two close countries (Bosnia Herzegovina and Croatia). One of the used scales concerned general interest and featured items such as "If an astronomy course was organized in my school I would like to attend it" and "I would like to learn astronomy as an elective school subject " that capture the engagement dimension of interest. Results show that students of both countries were on average interested in astronomy, although it is formally taught neither at the primary nor at the high school level. While valuable, the survey was not subjected to rigorous statistical analysis to establish its validity and reliability. Bartlett and colleagues [18] used an exploratory factor analysis approach to develop a multidimensional instrument to measure Astronomy and Science Student Attitude (ASSA). One scale, students' interest in astronomy captured the interest construct, while the remaining seven scales concerned aspects, such as practical work in science or future aspirations in science. The interest in astronomy scale featured seven items (e.g., "I find astronomy interesting" and "I feel drawn to the night sky"), showing high reliability (reported Cronbach's alpha is 0.86). As we will discuss later, we chose the interest scale from the ASSA instrument to measure students' interest in the present study.

\section{Utility value}

When the motivation in engaging with an activity or a content is not yet assimilated to an intrinsic satisfaction, but still viewed as a separable consequence, we refer to extrinsic motivation [101] or utility value in the expectancy-value model [102-104]. Utility value concerns how helpful a certain content or activity is to the aim of reaching an external goal, such as a future career [105]. An extended body of literature has proved that perceived value of a given task is correlated with interest, achievement, and performance [106-115], course enrollment decision [107,112], and interest in a given subject [113,116]. Moreover, previous findings in educational psychology [117] show a direct relationship between utility value and the process of interest development as conceptualized by Hidi and Renninger [92]. More specific to physics education, utility value seems relevant for the choice of physics at the secondary school and university level $[25,105]$. A recent study [118] shows that Finnish female physics undergraduates are more extrinsically motivated than their male peers and assign significantly more utility value to the physics choice for a nonacademic career (such as becoming a teacher). While utility value has not been included in the physics identity construct, Lock and colleagues [119] found a significant direct effect of physics identity on physics career choice and this effect is significantly different between girls and boys. Given the relationships between utility value and career choice in physics, the above evidence suggests that utility value can be treated as a further meaningful dimension in our astronomy identity model.

\section{Confidence}

Prior studies in STEM identity included competence belief as a key component of the model. On such basis, in this study, we will distinguish between conceptual knowledge, which concerns students' performance on a set of conceptual items, and competence belief, which we will operationalize with the widely accepted construct of confidence. Hence, we define confidence as the degree to which students feel that their answers to the conceptual items are correct. There is a growing body of literature in science education concerned with confidence assessment [120], since it has been proved that confidence plays a key role in decision-making processes [121-123]. Therefore, given that the choice of a career path in a STEM disciplinary area is the result of a decision-making process, it is reasonable to include confidence in a professional identity framework. Further reasons, to include confidence measure in the astronomy identity framework, are that prior research has shown that it is positively associated to motivation towards science $[124,125]$, as well as with science achievement [126-128], and persistence [128]. Moreover, an accurate self-evaluation of one's own ability in a given task is positively correlated with higher performances in that task [129-131]. Finally, it has been found that female students are less inclined to overestimate their achievements than boys [132-134]. The construct of 
confidence has been studied in physics education since the late 1990s. Hasan and colleagues [135] proposed that the degree of confidence one student has in their own ability to answer a test question can help identifying whether the wrong answer is due to a misconception, or to nonscientifically acceptable knowledge. For instance, a low confidence score ( $\leq 2$ out of 5 ) coupled to a correct answer signals potential guessing, while high confidence scores $(\geq 3$ out of 5) coupled to a wrong answer flag a potential misconception. Following this schema, Planinic and colleagues [136] found that students' misconceptions are more strongly rooted in dynamics rather than in electromagnetism. Similarly, Lindsey and Nagel [137] found that, in a classical mechanics conceptual test, students who obtained low scores tended to show more confidence in their answers than students who scored better. Such a result was confirmed by our recent study in introductory quantum mechanics [138]. What prior studies in physics education clearly point out is that performance belief is not the same as actual performance in a given task. As further example, in a study about mechanical waves, the authors found that students expressed higher levels of confidence in nonscientifically correct responses to items whose content had been actually targeted in the curriculum [139]. Finally, we only found one study that exploited the confidence construct in astronomy education research. More specifically, in a questionnaire about the expansion of the Universe, Aretz and colleagues [140] found that only 235 out of 821 students in the sample expressed a high degree of confidence ( $\geq 4$ out of 5 ) in their answers, thus suggesting that the majority of students had guessed their answers.

\section{E. Conceptual knowledge}

Prior studies in the STEM field [39] thoroughly predict that stronger identity leads to higher academic achievements and higher grades [141]. However, other studies suggest that the relationship between identity and knowledge works also the other way around [142]. Namely, the higher the knowledge level in a disciplinary area, the higher the discipline identification. Seyranian et al. [27] tested the hypothesis that higher grades in a physics course and higher scores in the Force Concept Inventory (FCI) [143] were related to higher levels of physics career identification. They found a significant effect of higher grades but not of FCI scores. This result clearly calls for more research to understand the relationship between disciplinary knowledge and identity. Hence, it seems reasonable to include also conceptual knowledge in the astronomy identity framework. In this study, we restrict our attention to students' knowledge about basic astronomy topics, such as seasonal changes, lunar phases, and solar and lunar eclipses. The main reason for such a choice of topics is that students' alternative conceptions about these phenomena have been thoroughly researched [144,145]. Moreover, previous studies [146,147] showed that these phenomena are strongly connected from the cognitive viewpoint. Finally, these topics form a knowledge base on which to build the learning of more complex concepts, such as stars' structure or universe evolution.

\section{F. The astronomy identity framework}

Based on the above reviewed literature, we propose an astronomy identity framework that features the following dimensions:

- interest: the personal predisposition to learn and understand astronomy and to engage in voluntary activities about it;

- utility value: the perceived importance of astronomy for personal goals;

- confidence: the self-assessment of one's own performance in an astronomy-related task;

- conceptual knowledge: the actual performance in an astronomy-related task.

The main aim is to examine how primary and lower secondary school students see themselves in relation to astronomy, using the four above dimensions as meaningful framework. The model is visually represented in Fig. 1. The hypothesized paths are based on the literature review and shall be tested against data evidence. Despite that our model draws from prior studies in STEM identity, there are some important differences with other disciplinary identities in the hypothesized structural relationships. First of all, from prior studies about confidence, we hypothesize its direct effect on knowledge as well as on the identity itself. Moreover, since both disciplinary interest and identity develop from early childhood [91], studying the role of interest may be particularly important for younger pupils who have not yet shown a strong commitment to a particular career. In other words, interest may be a precursor of science identity [45]. For the same reason, we hypothesize that it is interest, along with confidence and knowledge, that could affect the utility value given that, at that age, students' interest in a future career cannot be completely developed [91]. In turn, such perceived utility value can shape the astronomy identity. Second, we have not included the dimensions of recognition and sense of belonging. The main reason is that these constructs, in previous identity studies with young students, referred generically to the school context, with no relationship to a specific discipline. For instance, Capobianco et al. [148] initially envisaged as relevant for the engineering identity the childrens' sense of belonging or attachment to their school. However, they found that the sense of belonging to the school was not as important as they originally hypothesized. We propose as possible explanation for their result that engineering (as well as astronomy) does not correspond to any specific school subject and, therefore, it does not make any sense to ask primary and middle school students if they feel they belong to an engineering or astronomy community. For a similar reason, we left out in 


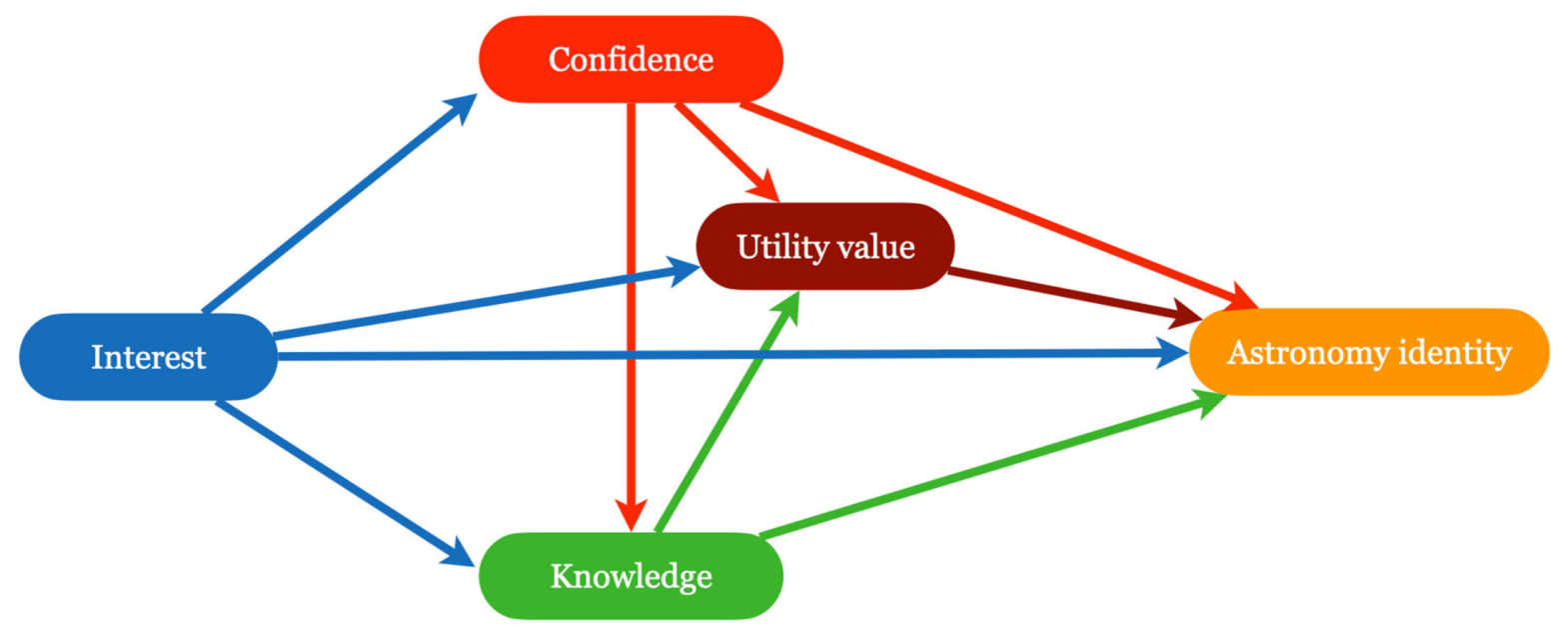

FIG. 1. Model of astronomy identity framework. Arrows represent the hypothesized paths.

our model the recognition in astronomy by school mates or influential others, such as the teacher. The reason is that astronomy in the Italian curriculum is just a small portion of a much broader school subject, i.e., science, so there are no grades or assessments that are specific to astronomy. As a consequence, as also suggested by Capobianco et al. [148], younger students may not be cognitively mature enough to discern recognition by significant others in classroombased science and astronomy concepts. Finally, as an exploratory focus, the current study also examined whether certain paths depend on gender and age. Given the novelty of our framework, we will investigate all possible differences in the model paths between girls and boys and look for possible effects of age. In the latter case, we acknowledge that students' astronomy identity depends on their learning experiences with astronomy, both in the classroom or in more informal settings.

\section{G. Research questions and hypothesis}

In an effort to address the hypothesized relationships between the constructs that constitute the astronomy identity framework, we propose the following research questions as a focus of this study:

RQ1: How do interest, utility value, confidence, and knowledge contribute to the astronomy identity?

RQ2: Are the constructs and pathways in the astronomy identity model different for girls and boys?

RQ3: How do the constructs and pathways in the astronomy identity model change with age, from primary to lower secondary school?

\section{METHODS}

\section{A. Sample and instructional context}

This study draws on survey data collected from a convenience sample of students from seven public schools located in two different districts in central and southern
Italy. Overall, the involved students were 893 (470 girls, $52.6 \%$; average age $=11.2 \pm 1.5 \mathrm{yr}$ ) from 5th to 9th grade. The reason for including students of this age range is related to prior studies that suggest professional identity develops already at precollege level [148,149]. Table I summarizes the demographics of the sample. At these school levels, the teaching of targeted astronomical topics-seasonal changes, lunar phases, and solar and lunar eclipses-is greatly fragmented within the science syllabus. In particular, curriculum guidelines provide few and scanty indications about the aim of the astronomy teaching: "to observe, model, and interpret the most evident celestial phenomena, through the observation of the night and morning sky, using planetariums or computer-based simulations; to reconstruct the motions of the Earth, on which the day-night cycle and seasonal changes depend; to construct three-dimensional models also in relationships with historical evolution (from geocentric to heliocentric system) of astronomy" [150,151]. The Italian Ministry of Education indications do not provide a clear sequence of topics to follow. However there is a commonly adopted activity sequence guided by the textbooks. For astronomy, at primary school level, the sequence is roughly the following: time measurements, Sun's path, day-night cycle, seasonal changes; Moon motion, solar system (5th grade). At lower secondary school level, the sequence is the following: solar system, motions of Earth, day-night cycle,

TABLE I. Descriptive statistics of the sample.

\begin{tabular}{lcccccc}
\hline \hline & & \multicolumn{2}{c}{ Gender } & & \multicolumn{2}{c}{ Age (yr) } \\
\cline { 3 - 4 } & $n$ & Boys & Girls & & Mean & S.D. \\
\hline Overall & 893 & 423 & 470 & & 11.2 & 1.5 \\
5th & 340 & 162 & 178 & & 9.9 & 0.6 \\
6th & 284 & 141 & 143 & & 11.1 & 0.4 \\
8th & 220 & 100 & 120 & & 13.0 & 0.4 \\
9th & 49 & 20 & 29 & & 14.3 & 0.5 \\
\hline \hline
\end{tabular}


qualitative description of seasonal changes (6th grade); Moon phases, solar and lunar eclipses (8th grade); Earth's movement around Sun and seasonal changes, Moon's movement around Earth, phases and eclipses (9th grade). While the same topic is addressed at different school level, the pedagogical approaches are clearly different. Roughly, at primary school level, observations and qualitative descriptions are privileged. At the lower secondary school level, especially at 9 th grade, some mechanisms underlying the targeted phenomena are also provided. However, we note that, generally, classes at both school levels are lecture based, with few practical activities. Moreover, usually, both primary and lower secondary school teachers do not usually possess a specialized degree in astronomy or physics, so when possible, astronomy teaching is carried out in collaboration with external experts in activities organized by local astronomical observatories or planetariums. Given such variability in the teaching background, we decided to leave out in the analysis the teachers' experience, content knowledge, and other variables related to teaching practice of the involved sample. We will discuss such choice in Sec. VIII.

\section{B. Instrument}

The instrument consisted of four parts: (i) interest towards astronomy (5 items), (ii) astronomy identity (1 item), (iii) utility value of astronomy (1 item), and (iv) a conceptual test about seasonal changes, lunar and solar eclipses, and lunar phases (6 or 9 items, see below). To measure the confidence construct, each item of the conceptual test featured a second tier asking respondents the extent to which they felt confident in the given answer. Items in (i)-(iii) parts were rated on a 5-point Likert scale from 1 (strongly disagree) to 5 (strongly agree). Items of the conceptual test were all in multiple choice format with four alternatives, only one of which was true (score $=1 \mathrm{pt}$ ), with the remaining three corresponding to well-known misconceptions about the targeted phenomenon $(\mathrm{score}=0 \mathrm{pt})$. Confidence scale for each item ranged from 1 (not at all confident) to 5 (completely confident). At the beginning of the instrument, students had to report their gender, age, and grade level. As mentioned in Sec. II B, the interest scale was adapted from the 7-item students' interest in astronomy scale of the ASSA instrument [18]. After a first translation in Italian, face validity of the items was discussed with professional astrophysicists who would have participated in the data collection process and with three experienced primary teachers of the pupils involved in the study. As a result, one item was left out in the survey ("I am interested in the stories behind the constellations") because, when translated in Italian, it was considered unclear (story can be translated in Italian also as fairy tale). Note that this item had also the lowest factor loading (0.56) on the original scale. Another item ("I would like to undertake astronomy as a career") was used for the astronomy identity construct after a small rephrasing to make it more straightforward ("I would like to be an astronomer"). A further item, developed by reviewing the literature, was used for the utility value construct ("I think that learning astronomy is useful for my future"). The final used items are summarized in Table II. The conceptual test about seasonal changes, lunar phases, and eclipses was based on an instrument developed and validated in a previous study by our group [146]. To take into account possible differences due to the different school level, we designed two different forms of the test: one, which targeted 5th and 6th grade students, consisted of six items, two for each phenomenon, and another, which targeted 8th and 9th grade students, featuring nine items, three for each phenomenon. The two forms of the conceptual test are reported in the Supplemental Material, Sec. A [152].

\section{Procedure}

The survey was conducted between December 2019 and May 2020 in two different phases. We started administering the survey to students involved in in-person activities carried out at INAF-Capodimonte Astronomical Observatory in southern Italy. Schools usually apply to participate to this kind of in-person activities at the beginning of the school year. The observatory staff then proposes a meeting schedule to which the schools should conform. The activities involve the whole class and substitute in the scheduled day of regular classroom teaching (duration: about $4 \mathrm{~h}$ ). Hence, the pupils do not choose to participate voluntary in the activities. We purposefully maintained this procedure to avoid bias due to motivation towards the addressed contents or environment. However, since March 2020, due to the lockdown enforced by the Italian government to cope with the COVID-19 pandemic, we were compelled to administer an online survey. The procedure in this second phase was as follows. We contacted by email the same schools that agreed to participate to the in-person activity and that where scheduled for the time period March-May 2020 proposing an alternative online activity. Then, the schools that accepted our proposal signed a formal agreement to let their students participate. Also in this case, the activity substituted the regular classroom remote teaching $(2 \mathrm{~h})$. Table III summarizes the distribution of collected answers in the two phases.

TABLE II. Items used to measure interest towards astronomy, astronomy identity, and astronomy utility value.

\begin{tabular}{ll}
\hline Interest & I like to observe the night sky \\
& I would like to do astronomy as a hobby \\
& I would like to use a telescope \\
& I find astronomy interesting \\
I have a strong interest in learning things \\
about the Universe \\
Identity & I would like to be an astronomer \\
Utility value & I think that learning astronomy is useful \\
& for my future \\
\hline \hline
\end{tabular}


TABLE III. Number of questionnaires collected by grade and modality (in-person and online).

\begin{tabular}{lccc}
\hline \hline & & \multicolumn{2}{c}{ Modality } \\
\cline { 3 - 4 } & $n$ & In-person & Online \\
\hline Overall & 893 & 224 & 669 \\
5th & 340 & 179 & 161 \\
6th & 284 & 0 & 284 \\
8th & 220 & 45 & 175 \\
9th & 49 & 0 & 49 \\
\hline \hline
\end{tabular}

During the in-person phase, the survey was printed out and administered by professional astrophysicists of the hosting observatory before the beginning of the planned activity. In the online phase, the students answered the survey by using a link that was uploaded by their science teachers into the same virtual environment, in which the remote class activities were normally carried out. To ensure as much as possible the validity and uniqueness of answers in the online phase, the survey was administered and completed at the beginning of the remote activity and the link closed right after. It was clarified to the students that the survey was not aimed at assessing their knowledge and that their teachers had no access to their score. The teachers collected the answers in an Excel file using the virtual learning environment tools, and then they sent us the file with the students' answers after having anonymized them. In both modalities, the involved students had already addressed the targeted topics (seasons, Moon phases, and eclipses) according to their syllabus before filling in the survey. In both in-person and remote modalities, the whole class was involved. On average, it took about $25 \mathrm{~min}$ to complete the survey. After inspection that the preliminary descriptive statistics for the two groups was not statistically different, we decided to combine the two groups for the complete statistical analyses.

\section{DATA ANALYSIS}

We first performed a descriptive statistical analysis of the collected data. Subjects with 5 or more missing answers were excluded, for a total of 88 subjects removed. All 88 removed subjects had completed the online survey. The distribution was the following: 37 subjects from 5 th grade dataset, 20 subjects from 6th grade, 31 subjects from 8th grade. None of the 9th grade subjects was removed. Missing answers from the 805 remaining subjects were calculated using mean imputation. We investigated score differences between girls and boys in each item of the interest toward astronomy scale, and for the confidence, knowledge, and identity variables using multiple $t$ tests. We also investigated differences in the same variables across school levels using a one-way analysis of variance. Then, we tested our model using confirmatory factor analysis (CFA) and structural equation modeling (SEM). The CFA helped establish the construct validity of the interest toward astronomy scale. Several measures were used to assess the single-factor structure of the interest scale and determine which items were to be retained. First, we inspected the following goodness-of-fit indices: ratio of chi squared to degrees of freedom $(\tilde{\chi})$, normed fit index (NFI), incremental fit index (IFI), Tucker-Lewis index (TLI), comparative fit index (CFI), and root mean square error of approximation (RMSEA). Acceptable values for $\tilde{\chi}$ are between 2 and 3 [153], with $p>0.05$, although for large samples $(N>200)$, we expect a significant chi square also for good models [154]. For IFI, TLI, and CFI acceptable values are $\geq 0.95$, while for RMSEA values between 0.06 and 0.08 indicate mediocre fit, values between 0.05 and 0.06 indicate acceptable fit, and values $\leq 0.05$ indicate a good model [155]. Since we were investigating a single-factor structure, we identified residual correlation between the items in order to improve the fit. Then, we used average variance extracted (AVE), composite reliability (CR), and Cronbach's alpha as indices to assess the convergent validity of the factor structure which resulted from the fit. Finally, we performed a multi-group analysis to test measurement invariance between girls and boys. Significance of the chi-squared difference and changes in the NFI, IFI, and TLI indices were used to assess whether the factor structure was invariant between the two groups. To conduct this test, we compared the unconstrained (baseline) model with a model with all regression paths constrained. Once the construct validity for the interest toward astronomy scale was established through CFA, we assessed the structural relationships between the interest, confidence, knowledge, utility, and identity constructs through SEM. There are several reasons for using SEM analysis in this study. First, it has been extensively used in prior studies about physics and engineering identity $[34,156]$. Second, SEM allows us to test direct causal, indirect causal, and spurious relationships between the variables of the model. Third, SEM analysis allows for multigroup analysis, namely, to test the null hypothesis that measurement and structural relationships do not depend on the membership of a specific group of individuals. The values of the interest construct used in the hypothesized model were obtained by data imputation from the performed CFA. Given the different number of items used in the two forms of the test, values of the knowledge construct for each student were obtained by averaging the answers to the conceptual test items. Similarly, values of the confidence construct for each student were obtained by averaging the answers to each confidence tier in the conceptual test. Utility and identity construct values corresponded to the scores given by each student in the respective items. The same indices used in the CFA were adopted also to assess goodness of fit of the hypothesized model: $\tilde{\chi}$, NFI, IFI, TLI, CFI, and RMSEA. Nonsignificant regression coefficients were suppressed to improve fit indices. The significance of indirect effects was assessed 
by performing bootstrap analysis and by calculating biascorrected confidence intervals. Then, multigroup SEM was performed to inspect the structural invariance of the resulting model between girls and boys. Two different approaches were carried out to assess invariance: chisquared difference and path difference. In the first approach, we contrasted the baseline model, where all structural paths are free, with (i) a model with all significant paths constrained; (ii) subsequent models in which one regression path at the time is constrained. In the second approach, we concurrently compared the significance of the difference between the regression and indirect paths for girls and boys. Finally, we repeated the multigroup analysis with the age variable as covariate, to inspect possible differential gender effects. Descriptive statistical analysis was performed using SPSS v.26, while both CFA and SEM were run using AMOS v.20.

\section{RESULTS}

\section{A. Descriptive statistics}

We report in Supplemental Material, Sec. B [152] the descriptive statistics of the measured variables: interest, perceived utility value, identity, confidence, and conceptual knowledge. Mean values for each grade level involved in the sample, for girls and boys and corresponding $t$ tests and analysis of variance tests are reported. Interest in astronomy, perceived utility, and identity decrease significantly as grade increases (see Table S1 [152]). In particular, 5 th graders scored higher in all items. Differences between girls and boys are significantly different for "I like to observe the night sky" item consistently across grades, while for the remaining items differences depend on the grade level. For instance, for the "I would like to do astronomy as a hobby" item, the differences are statistically significant only for 5th graders. Similarly, for the "I would like to be an astronomer" item, the differences are statistically significant for 5th and 8th graders. Concerning knowledge about the targeted astronomical phenomena (see Table S2 [152]), overall, the sample answered correctly on average to less than $50 \%$ of the questions (mean: $0.42 \pm 0.22)$. When analyzing the distribution of students' answers for the specific astronomy phenomena, we note that students scored lowest in seasonal change items (mean: $0.37 \pm 0.33$ ) and Moon phases (mean: $0.40 \pm 0.33$ ), while scores slightly improve for eclipses (mean: $0.45 \pm 0.36$ ). The differences between the scores are statistically significant $(t>3.435, p<0.001)$. Also, when looking at the performances across grade levels we note that the scores are significantly higher for 5th and 6th grade students, but still under the $50 \%$ threshold. When inspecting confidence scores, the sample is, on average, confident in their answers (mean: $3.30 \pm 0.83$ ), with no statistical differences between girls and boys (3.25 vs 3.35). However, confidence in answers about seasons and eclipses is higher than the confidence in answers about Moon phases (3.43 and 3.36 vs 3.09 , respectively) and the differences are statistically significant $\left(t>9.102, p<10^{-4}\right)$. When looking at confidence trends across grade level, we note that 5 th and 6th grade pupils are consistently the most confident for the three phenomena.

\section{B. Confirmatory factor analysis}

Figure 2 reports the factor structure of the interest towards astronomy scale. All regression weights are significant at $p<0.001$ level and greater than 0.50 . We allowed two interitem residual correlations (I like to observe the night sky with I would like to do astronomy as a hobby and I would like to use a telescope, respectively), since these three items all refer to amateur interest in astronomy. The final $\tilde{\chi}$ was 2.630 with $p=0.048$, which suggests a well-fit model. The other fit indices were also satisfactory: NFI $=0.99$, IFI $=0.99$, $\mathrm{TLI}=0.99, \mathrm{CFI}=0.99$, and RMSEA $=0.045$, with confidence interval $=(0.003 ; 0.085), p=0.515$. The value of RMSEA indicates a good model fit [157]. Average variance extracted was 0.48 , while composite reliability and Cronbach's alpha were both excellent (0.82). These values support that the interest toward astronomy construct is adequately measured by the scale items. Multigroup analysis supports measurement invariance of the interest construct for gender $(\Delta \chi=10.388, d f=5, p=0.065 ; \Delta \mathrm{NFI}=0.008$; $\Delta \mathrm{IFI}=0.008 ; \Delta \mathrm{TLI}=-0.007)$.

\section{Structural equation modeling}

Figure 3 illustrates the final structural model, with only significant paths included. All fit indices suggest that the model adequately fits the data: $\tilde{\chi}=1.447, d f=5$, $p=0.204 ; \mathrm{NFI}=0.99 ; \mathrm{IFI}=0.99 ; \mathrm{TLI}=0.99 ; \mathrm{CFI}=$ 0.99 ; RMSEA $=0.024$, confidence interval: $(0.000$; $0.058), p=0.881$. Two indirect effects are also significant:

$$
\text { Interest } \rightarrow \text { Confidence } \rightarrow \text { Knowledge, }
$$

standardized estimate $=0.063$, bootstrap two-tailed confidence interval: $(0.017 ; 0.036), p=0.008$ and

$$
\text { Interest } \rightarrow \text { Utility } \rightarrow \text { Identity, }
$$

standardized estimate $=0.031$, bootstrap two-tailed confidence interval: $(0.026 ; 0.117), p=0.019$. This means that the effect of interest on knowledge is mediated by confidence and that the effect of interest on identity is also mediated by the utility value. Table IV report the results of the multigroup analysis using the chi-squared difference approach. Values reported in the first row support structural invariance of the astronomy identity model, since the difference in chi squared between the unconstrained and fully constrained models is not significant. When looking at the subsequent rows, the chi-squared difference is significant only when constraining the Interest $\rightarrow$ Identity path. Therefore, the effect of interest 


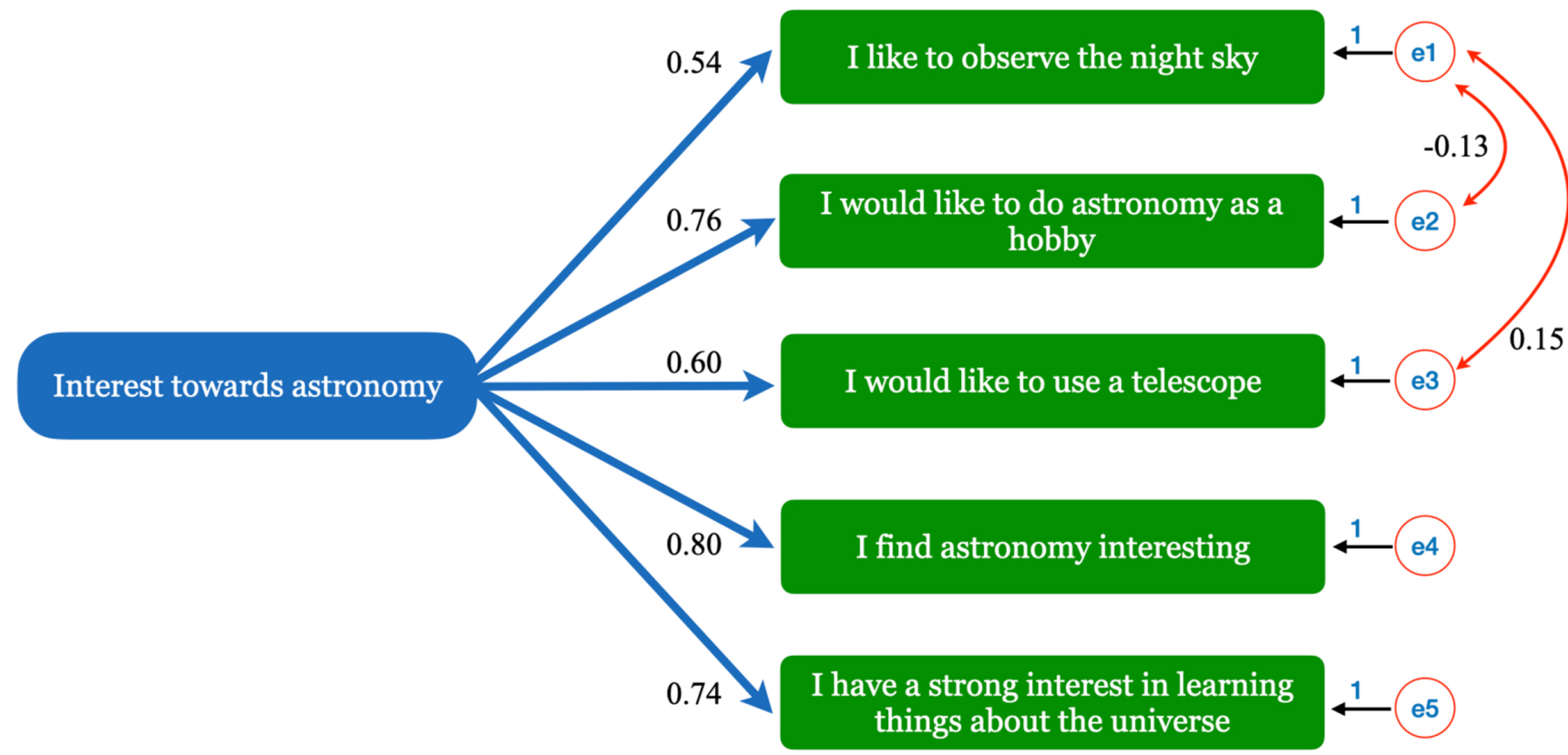

FIG. 2. Factor structure of the interest towards astronomy scale $(N=805)$. Regression weights are standardized. Each arrow with the line connecting two variables in the diagram indicates the direction of regression. Two headed arrows represent the residual correlations of the items.

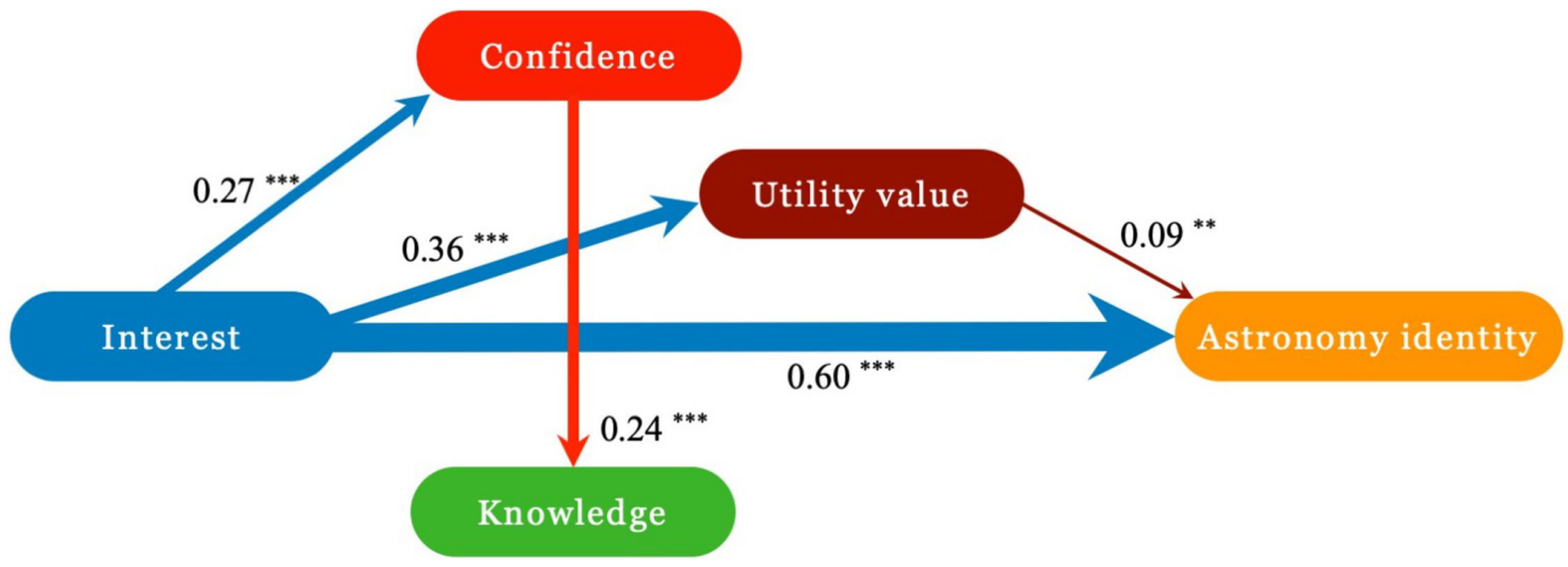

FIG. 3. Structural model of astronomy identity. Regression weights are standardized. Each arrow with the line connecting two variables in the diagram indicates the direction of regression. $* * p<0.01 ; * * * p<0.001$.

on identity is different for boys and girls. We note that, in the unconstrained model, the estimate of Interest $\rightarrow$ Identity path for girls is 0.615 , while for boys is 0.578 . Table V report the differences between the regression paths, as well as the differences between the indirect paths for girls and boys, with their corresponding confidence interval and level of significance. We note that only the Interest $\rightarrow$ Identity difference is statistically significant, in agreement with what we found in the analysis of the chi-squared difference between the unconstrained model and the model in which the Interest $\rightarrow$ Identity path was constrained. In particular, the effect of interest on astronomy identity is significantly stronger for girls. While the differences between the indirect paths for girls and boys are not statistically significant, we note that the indirect path Interest $\rightarrow$ Utility $\rightarrow$ Identity is statistically significant for boys [estimate: 0.088 , confidence interval: $(0.020 ; 0.152), p=0.025]$ but not for girls [estimate: 0.050 , confidence interval: $(0.000 ; 0.112), p=0.101]$. This means that the utility value significantly mediates the effect of interest on identity only for boys. On the contrary, the 
TABLE IV. Multigroup analysis for girls and boys for the model in Fig. 3.

\begin{tabular}{lccccrrr}
\hline \hline Model & DF & $\Delta \chi$ & P & $\Delta$ NFI & $\Delta$ IFI & $\Delta$ RFI & $\Delta$ TLI \\
\hline Structural weights (all paths constrained) & 5 & 6.614 & 0.251 & 0.010 & 0.010 & 0.002 & 0.002 \\
Interest $\rightarrow$ Identity & 1 & 6.405 & 0.011 & 0.010 & 0.010 & 0.015 & 0.015 \\
Utility $\rightarrow$ Identity & 1 & 0.722 & 0.395 & 0.001 & 0.001 & -0.001 & -0.001 \\
Interest $\rightarrow$ Utility & 1 & 0.022 & 0.882 & 0.000 & 0.000 & -0.003 & -0.003 \\
Interest $\rightarrow$ Confidence & 1 & 0.028 & 0.867 & 0.000 & 0.000 & -0.003 & -0.003 \\
Confidence $\rightarrow$ Knowledge & 1 & 0.149 & 0.699 & 0.000 & 0.000 & -0.003 & -0.003 \\
\hline \hline
\end{tabular}

TABLE V. Path differences between girls and boys for the model in Fig. 3.

\begin{tabular}{lcccc}
\hline \hline Path & Estimate $^{\mathrm{a}}$ & Lower & Upper & $\mathrm{P}$ \\
\hline Interest $\rightarrow$ Identity & 0.318 & 0.158 & 0.508 & 0.015 \\
Interest $\rightarrow$ Confidence & 0.005 & -0.052 & 0.051 & 0.990 \\
Utility $\rightarrow$ Identity & -0.045 & -0.124 & 0.072 & 0.460 \\
Interest $\rightarrow$ Utility & 0.023 & -0.225 & 0.302 & 0.884 \\
Confidence $\rightarrow$ Knowledge & 0.025 & -0.093 & 0.101 & 0.809 \\
Interest $\rightarrow$ Confidence $\rightarrow$ Knowledge & 0.004 & -0.014 & 0.020 & 0.768 \\
Interest $\rightarrow$ Utility $\rightarrow$ Identity & -0.038 & -0.119 & 0.067 & 0.469 \\
\hline \hline
\end{tabular}

\footnotetext{
${ }^{\mathrm{a}}$ Unstandardized.
}

Interest $\rightarrow$ Confidence $\rightarrow$ Knowledge indirect path is statistically significant for both girls and boys [girls estimate: 0.028 , confidence interval: $(0.017 ; 0.042), p=0.016$; boys estimate: 0.024 , confidence interval:(0.014;0.038), $p=0.007]$. Hence, confidence is a mediator for interest on knowledge for both girls and boys. Figure 4 reports the structural model of Fig. 3 after inserting the age variable. The structural relationships remain the same; namely, all paths have roughly the same strength and significance, as in the previous model. Consistently with findings from the descriptive statistical analysis, we note that age and interest are significantly anticorrelated $(p<0.001)$ and that there is a significant direct negative effect of age on confidence, which partly moderates the effect of interest on confidence. The effect of age on identity is not statistically significant, while the effect of age on utility value is only significant at $p<0.05$. We hence investigated possible differences in the structural model of Fig. 4 due to gender. Table VI reports

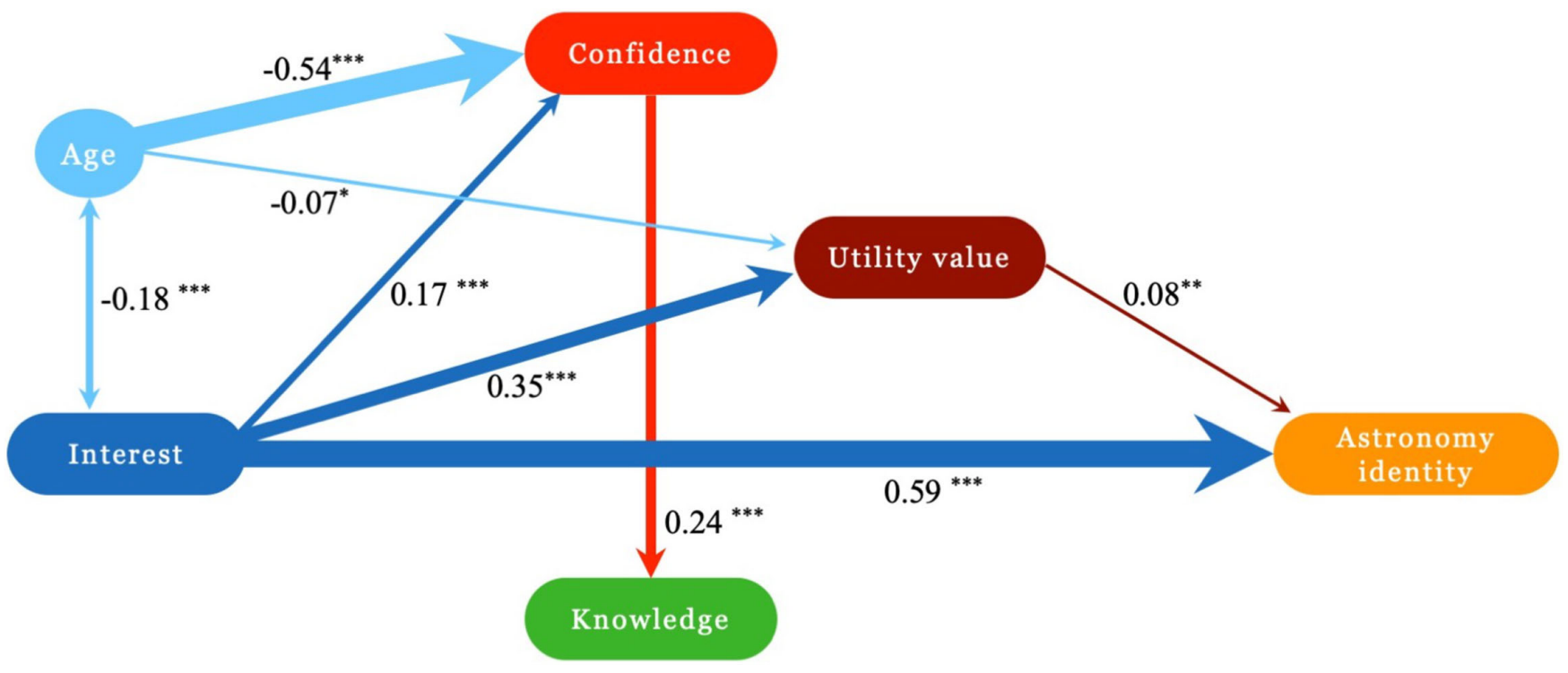

FIG. 4. Structural model of astronomy identity with age variable as a covariate. Regression weights are standardized. Two headed arrows represent item correlations. Each arrow with the line connecting two variables in the diagram indicates the direction of regression. $* p<0.05 ; * * p<0.01 ; * * * p<0.001$. 
TABLE VI. Multigroup analysis for girls and boys for the model in Fig. 4.

\begin{tabular}{|c|c|c|c|c|c|c|c|}
\hline Model & $\Delta \mathrm{F}$ & $\Delta \chi$ & $\mathrm{P}$ & $\Delta \mathrm{NFI}$ & $\Delta \mathrm{IFI}$ & $\Delta \mathrm{RFI}$ & $\Delta \mathrm{TLI}$ \\
\hline Structural weights & 9 & 24.372 & 0.004 & 0.025 & 0.025 & 0.024 & 0.025 \\
\hline Interest $\rightarrow$ & 1 & 3.776 & 0.052 & 0.004 & 0.004 & 0.008 & 0.008 \\
\hline Utility $\rightarrow$ Identity & 1 & 1.287 & 0.257 & 0.001 & 0.001 & 0.001 & 0.001 \\
\hline Interest $\rightarrow$ Utility & 1 & 0.024 & 0.876 & 0.000 & 0.000 & -0.003 & -0.003 \\
\hline Interest $\rightarrow$ Confidence & 1 & 0.293 & 0.588 & 0.000 & 0.000 & -0.002 & -0.002 \\
\hline Confidence $\rightarrow$ Knowledge & 1 & 0.986 & 0.321 & 0.001 & 0.001 & 0.000 & 0.000 \\
\hline Age $\rightarrow$ Confidence & 1 & 0.617 & 0.432 & 0.001 & 0.001 & -0.001 & -0.001 \\
\hline Age $\rightarrow$ Identity & 1 & 14.024 & 0.000 & 0.014 & 0.014 & 0.036 & 0.037 \\
\hline Age $\rightarrow$ Knowledge & 1 & 1.444 & 0.229 & 0.001 & 0.001 & 0.001 & 0.001 \\
\hline Age $\rightarrow$ Utility & 1 & 1.630 & 0.202 & 0.002 & 0.002 & 0.002 & 0.002 \\
\hline Interest $\rightarrow$ Age & 1 & 0.085 & 0.771 & 0.000 & 0.000 & -0.003 & -0.003 \\
\hline
\end{tabular}

TABLE VII. Path differences between girls and boys for the model in Fig. 4.

\begin{tabular}{lrrrc}
\hline \hline Path & Estimate $^{\mathrm{a}}$ & Lower & Upper & $\mathrm{P}$ \\
\hline Age $\rightarrow$ Confidence & -0.007 & $-0,024$ & 0.006 & 0.309 \\
Age $\rightarrow$ Identity & -0.167 & -0.224 & -0.070 & 0.023 \\
Age $\rightarrow$ Knowledge & 0.015 & -0.004 & 0.034 & 0.147 \\
Age $\rightarrow$ Utility & 0.077 & -0.182 & 0.028 & 0.265 \\
\hline \hline
\end{tabular}

${ }^{\mathrm{a}}$ Unstandardized.

the multigroup analysis using the chi-squared difference approach. We note from the values of the first row that structural invariance does not hold $(p<0.01)$; therefore, certain paths are not invariant between girls and boys. By looking at Table VI, we find that the only path that changes significantly the chi-square, when adopting the unconstrained model as baseline, is the Age $\rightarrow$ Identity path $(p<0.001)$. The standardized regression weight of this path for girls is $-0.13(p<0.01)$, while for boys is $+0.08(p<0.05)$. Therefore, age acts differently on girls' astronomy identity in comparison to boys' identity. This evidence is confirmed when analyzing the differences for the age paths between girls and boys, reported in Table VII. The difference for the Age $\rightarrow$ Identity path is negative, as expected (regression path is negative for girls, while for boys it is positive) and is statistically significant at $p<0.05$ level. In other words, astronomy identity as a function of age decreases more rapidly for girls.

\section{DISCUSSION}

Literature in science education has increasingly focused on students' STEM identity, as a relevant construct to understand the way students see themselves in relation to school disciplines [36]. In particular, studies have focused on professional identity, such as physicist or engineer, as a way to understand motivations underlying students' choices at the undergraduate level [149]. Indeed, prior research studies clearly suggest that career orientations develop since precollege school $[148,149,158]$. The present study is the first application, using quantitative measures, of a professional identity framework in astronomy education, which extends its scope to a sample of upper elementary and middle school students. Moreover we looked at possible differences in the astronomy identity due to gender and age. While previous studies in astronomy education research [98] were limited to investigate separately the effect of interest and self-efficacy on students' conceptual understanding, our framework attempts at providing a more complete picture of how affective, cognitive, and metacognitive constructs interact within the disciplinary context of astronomy. To strengthen our measurement model, we validated an existing scale of interest towards astronomy using confirmatory factor analysis and adopted a conceptual test that targeted three familiar astronomical phenomena (seasonal changes, Moon phases, and eclipses) from previously validated instruments [146]. Below, we discuss the main results according to the research questions and hypotheses posed.

\section{A. How do interest, utility value, confidence, and knowledge contribute to the astronomy identity?}

Our results partly support the hypothesized identity model. In particular, interest towards astronomy has both a direct and an indirect effect on astronomy career identity. The indirect effect of interest on identity is mediated by utility value, namely, the form of motivation towards astronomy, which entails the student attributing future importance to personal behavior. Moreover, interest has an indirect effect also on astronomy knowledge mediated by confidence. The direct effect between interest and identity confirms the results of previous studies about physics identity (e.g., Ref. [119]), while the indirect effect of interest on astronomy knowledge confirms prior results about general scientific competencies [159], supporting the role of confidence as a relevant mediator of interest. Our study thus adds to the growing body of literature about the role of confidence as a predictor of students' performance in a variety of contexts [127]. On the opposite, the 
hypothesis that confidence and knowledge could have an effect on identity was not confirmed. Such results are in contrast with a recent study about physics identity [76], which, however, involved a completely different population of students (female undergraduates). The authors found that the belief in one's own ability to perform well in physics has a direct effect on physics identity. We see two main reasons for such differences. First, the difference in population of the studies. Students in our sample were of both genders and also much younger. Therefore their identity as scientists, astronomers in our case, is likely shaped more by their interest and learning experiences in astronomy rather than by their perception of ability, which actually affects only their performance. Second, the proposed questionnaire turned out to be difficult for the students in the sample (average percentage of correct answers was about 40\%) and this may have altered our measurement model. Finally, concerning the utility value, we found that (i) it directly affects astronomy career identity; (ii) it mediates the effect of interest on astronomy career identity. The first result is basically in agreement with findings of prior studies that report on utility value in physics as an important predictor for the choice of participation in physics activities $[160,161]$. Moreover, it has been found that utility value is an important component in profiles of students who choose physics at the post-secondary level $[25,105]$. The second result implies that, in young students as those in our sample, career expectation in a given discipline, namely, extrinsic motivation [101], is mainly driven by enjoyment and interest, i.e., by the intrinsic motivation in that discipline.

\section{B. Are the constructs and pathways in the astronomy identity model different for girls and boys?}

Drawing from prior studies (e.g., Refs. [54,76-78]), we hypothesized that the structural relationships in the astronomy identity model could depend on the gender of involved students. Our results partially supported this hypothesis. While structural model was invariant for gender, we found a significant difference in the path from interest toward identity between girls and boys. In particular, we found two important results: (i) the effect of interest on identity is greater for girls than for boys; (ii) utility value mediates the effect of interest on identity for boys but not for girls. The first result is in contrast with prior studies [119], where the authors report a stronger effect of interest on physics identity for boys. As also discussed above, this evidence may be due to both the different populations involved in the studies (primary and lower secondary school students vs college students) and to their different experience with the respective disciplines (astronomy and science, in general, vs physics). The second result may be due to a greater recognition by the boys of the utility value to learn astronomy for their future, in agreement with prior studies in physics [105]. Finally, while prior studies on physics identity focused only on the relationship between interest and perceived competency (confidence), our study included in the path also the actual performance and the comparison between girls and boys. Not only our result confirms that interest has a direct effect on confidence [76], but we also provide further evidence that interest has an indirect effect on actual knowledge mediated by confidence and that the path is significant for both girls and boys. This evidence is in agreement with prior studies about the role of confidence in performance in other science disciplines [120]. As an implication, our results suggest that teaching practices in astronomy should focus, in the future, not only on improving students' conceptual knowledge but also on providing them with opportunities that improve their confidence and perceived utility of astronomy.

\section{How do the constructs and pathways in the astronomy identity model change with age, from primary to lower secondary school?}

Data show that the age variable correlates significantly with interest and significantly affects confidence and utility value. The negative correlation between age and interest is in agreement with prior studies about students' motivation in physics and chemistry [162-164]. Similarly, also the negative effect of age on confidence has been detected in prior studies in other disciplines (e.g., Ref. [165]). The reason for the declining interest in astronomy can be likely due to a mismatch between students' expectations about astronomy and astronomy as taught at school [166]. Note that the effect of age on confidence likely moderates the effect of interest on confidence, thus suggesting that interest alone is not enough to sustain confidence in the long term. If we add to these findings that we also found a slightly significant negative effect of age on utility value, namely, how helpful for students is to learn astronomy at school for their future career, a strong message that emerges from our study is the need to find ways to support students' interest in doing astronomy and in being involved with it in the future. Perhaps, a better integration of informal activities in science centers or planetariums could result in learning experiences that maintain the interest in astronomy over a longer time. Finally, we found in the multigroup analysis that the path from age to identity is significantly different between girls and boys. In other words, the more the girls progress in their school level, the less they see themselves as astronomers. The opposite happens for boys. This result echoes that by Maltese and Tai [167], who found that girls show an early interest mostly in school science, while boys may be more engaged in self-initiated activities. As suggested also by prior studies [21], a possible way to improve students' interest in astronomy school topics could be to use up-to-date scenarios (e.g., the exploration of Mars, or the study of black holes). 


\section{CONCLUSIONS}

Overall, our results suggest new landscapes for research in astronomy education. First, more research is needed to understand whether girls' lower confidence in their performance could be related to implicit microaggressions. Prior studies [80] have found that women within physics and astronomy fields can experience different types of microaggressions, from disregarding their ideas to restricted laboratory access. Despite one single episode would not impact a girl's persistence in the field, the accumulation process may, on the long term, affect a woman's career in physics and astronomy. This literature may hence inform future studies that investigate the impact of perceived gender stereotypes on astronomy identity. Second, future studies should delve into testing the framework with older students (e.g., upper secondary school, undergraduate) in order to look for significant effects that we were unable to find, for instance, between confidence, conceptual knowledge, and astronomy identity. Furthermore, for older students, some additional constructs, such as self-efficacy, recognition, and sense of belonging could be included in the framework and provide further insights into the development of astronomy identity. In other words, it would be interesting to investigate whether students' astronomy identity changes when moving from high school to college level. Our results suggest that this shift is likely to happen, but what component of the model drives this shift? And how do high school learning experiences of physics and astrophysics influence this shift? Do activities in local planetariums and research institutes really have a role in shaping the students' astronomy identity or do they sustain only a situational interest? And, finally, how can science and physics teachers foster the development of a students' career identity in astronomy? Future research should inform these questions so to further validate the structural relationships of the model presented in this study.

\section{LIMITATIONS}

Being a first attempt to define the structural relationships of the astronomy identity, this study has several limitations. First of all, asking for demographics, and gender in particular, before taking the survey may have biased the girls' responses to the survey [168]. While we acknowledge such limitation, we remind that results from literature about stereotype threat are controversial and the extent to which it actually affects test performance is highly debated $[169,170]$. In particular, previous studies that tested the hypothesis that checking for gender before the test could affect girls' performance found no evidence of such effect [171-173]. However, to avoid any possible activation of a stereotype threat, in the revised version of the survey we will collect demographics of the sample with a separate sheet to be completed after the survey. Second, we acknowledge a possible limitation due to the fact that we coded gender data as a binary variable. However, gender identity is now conceptualized as a multidimensional social construct. Therefore, in the revised survey, we will collect data on gender using an open response format with the option of not answering. The third limitation relates to having a dataset that merges in-person and online surveys. While we enacted a rigorous procedure in agreement with the teachers of the involved students, we are aware that the online answers can be affected by biases that can lower the validity of the collected data. Symmetrically, although the whole class was involved, the in-person dataset could be biased in favor of boys, since they were collected in an environment, such as the astronomical observatory, which may be perceived differently by girls and boys. Fourth, we have used data coming from students who were taught about astronomy by different teachers, with a different background, a different experience, and that enact different approaches in teaching science. While we have suggested a possible relationship between teaching practice and the evolution of astronomy professional identity, however, it is beyond the scope of this introductory paper to fully envisage the relationships between teaching context and students' responses to the survey. Fifth, while large in size, the convenience sample limits the generalizability of the results to the broader population of 5th-9th graders. Therefore, we cannot claim that our model holds for all Italian pupils in that age range, although the recruited schools can be considered as representative of the Italian context. However, we are planning to extend our survey to a more representative sample chosen with a suitable procedure. Sixth, we collected data from different individuals from primary to lower secondary schools, while it would have been ideal to conduct a longitudinal study with the same subjects over time. Finally, although the CFA and SEM analyses were acceptable in terms of construct and structural validity, the proposed structural model of astronomy identity is by no means the best fit. As such, results in future studies could be improved, by adding more items related to the identity and utility value constructs and by widening the difficulty range of knowledge items.

\section{ACKNOWLEDGMENTS}

The authors are deeply grateful to Dr Silvio Leccia for his encouragement and many fruitful comments on the first draft of the manuscript; students, teachers, and principals of the involved schools: Istituto Comprensivo "D'Avino," Striano; Istituto Comprensivo "Cimarosa," Aversa; Istituto Comprensivo "Castro dei Volsci," Castro dei Volsci, Frosinone; Scuola Media Statale "G. Verga," Naples; XXI Circolo Didattico "Zuppetta-Mameli," Naples; Istituto d'Istruzione Superiore "Don Milani," Gragnano; and Dr. Antonella Liccardo, Dr. Stefania Russo, and Dr. Nicole Sorrentino for their useful suggestions. This research was funded by the Italian Ministry of University and Research under the Scientific Degree National Plan. 
[1] J. G. Sharp, Children's astronomical beliefs: A preliminary study of year 6 children in south west England, Int. J. Sci. Educ. 18, 685 (1996).

[2] R. Trumper, University students' conceptions of basic astronomy concepts, Phys. Educ. 35, 9 (2000).

[3] V. A. Atwood and R. K. Atwood, Preservice elementary teachers' conceptions of what causes night and day, School Sci. Math. 95, 290 (1995).

[4] K. J. Schoon, Students' alternative conceptions of Earth and space, J. Geol. Educ. 40, 209 (1992).

[5] S. Vosniadou and W. F. Brewer, Mental models of the day/night cycle, Cogn. Sci. 18, 123 (1994).

[6] J. Baxter, Children's understanding of familiar astronomical events, Int. J. Sci. Educ. 11, 502 (1989).

[7] R. Trumper, Teaching future teachers basic astronomy concepts, seasonal changes, at a time of reform in science education, J. Res. Sci. Teach. 43, 879 (2006).

[8] R. S. Lindell, Enhancing college students' understanding of lunar phases (2001), "ETD Collection" for University of Nebraska, Lincoln, AAI3022646, Ph.D. thesis, University of Nebraska, Lincoln, Nebraska.

[9] K. C. Trundle, R. K. Atwood, and J.E. Christopher, Fourth-grade elementary students' conceptions of standards-based lunar concepts, Int. J. Sci. Educ. 29, 595 (2007).

[10] I. Testa, S. Leccia, and E. Puddu, Astronomy textbook images: Do they really help students?, Phys. Educ. 49, 332 (2014).

[11] S. Galano, A. Colantonio, S. Leccia, I. Marzoli, E. Puddu, and I. Testa, Developing the use of visual representations to explain basic astronomy phenomena, Phys. Rev. Phys. Educ. Res. 14, 010145 (2018).

[12] A. Colantonio, S. Galano, S. Leccia, E. Puddu, and I. Testa, Design and development of a learning progression about stellar structure and evolution, Phys. Rev. Phys. Educ. Res. 14, 010143 (2018).

[13] L. Agan, Stellar ideas: Exploring students' understanding of stars, Astron. Educ. Rev. 3, 77 (2004).

[14] J. M. Bailey, E. E. Prather, B. Johnson, and T. F. Slater, College students' pre-instructional ideas about stars and star formation, Astron. Educ. Rev. 8, 010110 (2009).

[15] E. Prather, T. Slater, and E. Offerdahl, Hints of a fundamental misconception in cosmology, Astron. Educ. Rev. 1, 28 (2002).

[16] C. Wallace, E. Prather, and D. Duncan, A study of general education astronomy students' understandings of cosmology. Part IV. Common difficulties students experience with cosmology, Astron. Educ. Rev. 11, 010104-1 (2012).

[17] R. Jarman and L. McAleese, Physics for the star-gazer: pupils' attitudes to astronomy in the Northern Ireland Science Curriculum, Phys. Educ. 31, 223 (1996).

[18] S. Bartlett, M. Fitzgerald, D. Mckinnon, L. Danaia, and J. Lazendic-Galloway, Astronomy and science student attitudes: a short review and validation of a new instrument, J. Astron. Earth Sci. Educ. 5, 1 (2018).

[19] M. Marusic and Z. Hadzibegovic, Student attitudes towards astronomy: A bi-country questionnaire results, Rev. Mex. Fis. 64, 61 (2018).

[20] M. Fitzgerald, D. H. McKinnon, L. Danaia, and J. Deehan, A large-scale inquiry-based astronomy intervention project: Impact on students' content knowledge performance and views of their high school science classroom, Res. Sci. Educ. 46, 901 (2016).

[21] R. Beare, Investigation into the potential of investigative projects involving powerful robotic telescopes to inspire interest in science, Int. J. Sci. Educ. 29, 279 (2007).

[22] J. Osborne, S. Simon, and S. Collins, Attitudes towards science: A review of the literature and its implications, Int. J. Sci. Educ. 25, 1049 (2003).

[23] N. Reid and E. A. Skryabina, Attitudes towards physics, Res. Sci. Technol. Educ. 20, 67 (2002).

[24] M. E. Bathgate, C. D. Schunn, and R. Correnti, Children's motivation toward science across contexts, manner of interaction, and topic, Sci. Educ. 98, 189 (2014).

[25] P.-T. Oon and R. Subramaniam, Factors influencing singapore students' choice of physics as a tertiary field of study: A Rasch analysis, Int. J. Sci. Educ. 35, 86 (2013).

[26] A. M. Porter and R. Ivie, Women in physics and astronomy, in Women Physics and Astronomy 2019 (Statistical Research Center of the American Institute of Physics, 2019) unpublished.

[27] V. Seyranian, A. Madva, N. Duong, N. Abramzon, Y. Tibbetts, and J. M. Harackiewicz, The longitudinal effects of STEM identity and gender on flourishing and achievement in college physics, Int. J. STEM Educ. 5, 40 (2018).

[28] K. Robinson, Y. Lee, E. Bovee, T. Perez, S. Walton, D. Briedis, and L. Linnenbrink-Garcia, Motivation in transition: Development and roles of expectancy, task values, and costs in early college engineering, J. Educ. Psychol. 11, 1081 (2018).

[29] E. V. Slater, J. E. Morris, and D. McKinnon, Astronomy alternative conceptions in pre-adolescent students in Western Australia, Int. J. Sci. Educ. 40, 2158 (2018).

[30] P. Potvin and A. Hasni, Interest, motivation, and attitude towards science and technology at K-12 levels: A systematic review of 12 years of educational research, Stud. Sci. Educ. 50, 85 (2014).

[31] J. Eccles, Who am I and what am I going to do with my life? Personal and collective identities as motivators of action, Educ. Psychol. 44, 78 (2009).

[32] D. Oyserman, Not just any path: Implications of identitybased motivation for disparities in school outcomes, Econ. Educ. Rev. 33, 179 (2013).

[33] H. B. Carlone and A. Johnson, Understanding the science experiences of successful women of color: Science identity as an analytic lens, J. Res. Sci. Teach. 44, 1187 (2007).

[34] Z. Hazari, G. Sonnert, P. M. Sadler, and M.-C. Shanahan, Connecting high school physics experiences, outcome expectations, physics identity, and physics career choice: A gender study, J. Res. Sci. Teach. 47, 978 (2010).

[35] J. P. Gee, Identity as an analytic lens for research in education, Rev. Res. Educ. 25, 99 (2000).

[36] J. M. Kane, Young African American children constructing academic and disciplinary identities in an urban science classroom, Sci. Educ. 96, 457 (2012).

[37] M. M. Chemers, E. L. Zurbriggen, M. Syed, B. K. Goza, and S. Bearman, The role of efficacy and identity in science career commitment among underrepresented minority students, J. Soc. Issues 67, 469 (2011). 
[38] R. Kelly, O. M. Garr, K. Leahy, and M. Goos, An investigation of university students and professionals' professional STEM identity status, J. Sci. Educ. Technol. 29, 536 (2020).

[39] A. Y. Kim, G. M. Sinatra, and V. Seyranian, Developing a STEM identity among young women: A social identity perspective, Rev. Educ. Res. 88, 589 (2018).

[40] K. A. Robinson, T. Perez, J. H. Carmel, and L. Linnenbrink-Garcia, Science identity development trajectories in a gateway college chemistry course: Predictors and relations to achievement and STEM pursuit, Contemp. Educ. Psychol. 56, 180 (2019).

[41] P. R. Aschbacher, E. Li, and E. J. Roth, Is science me? High school students' identities, participation, and aspirations in science, engineering, and medicine, J. Res. Sci. Teach. 47, 564 (2010).

[42] L. Archer, J. DeWitt, J. Osborne, J. Dillon, B. Willis, and B. Wong, "Doing" science versus "being" a scientist: Examining 10/11-year-old school children's constructions of science through the lens of identity, Sci. Educ. 94, 617 (2010).

[43] A. Calabrese Barton, H. Kang, E. Tan, T. B. O’Neill, J. Bautista-Guerra, and C. Brecklin, Crafting a future in science: Tracing middle school girls' identity work over time and space, Am. Educ. Res. J. 50, 37 (2013).

[44] J. S. Brotman and F. M. Moore, Girls and science: A review of four themes in the science education literature, J. Res. Sci. Teach. 45, 971 (2008).

[45] G. Trujillo and K. D. Tanner, Considering the role of affect in learning: Monitoring students' self-efficacy, sense of belonging, and science identity, CBE Life Sci. Educ. 13, 6 (2014).

[46] P. Vincent-Ruz and C. D. Schunn, The nature of science identity and its role as the driver of student choices, Int. J. STEM Educ. 5, 48 (2018).

[47] A. Calabrese Barton and E. Tan, We be burnin'! Agency, identity, and science learning, J. Learn. Sci. 19, 187 (2010)

[48] J. F. Dovidio, S. L. Gaertner, Y. F. Niemann, and K. Snider, Racial, ethnic, and cultural differences in responding to distinctiveness and discrimination on campus: Stigma and common group identity, J. Soc. Issues 57, 167 (2001).

[49] A. Patrick, A. N. Prybutok, and M. Borrego, Predicting persistence in engineering through an engineering identity scale, Int. J. Eng. Educ. 34, 351 (2018).

[50] R. Robnett, The role of peer support for girls and women in STEM: Implications for identity and anticipated retention, Int. J. Gen. Sci. Technol. 5, 232 (2013), http://genderandset.open.ac.uk/index.php/genderandset/ article/view/299.

[51] E. Seymour and N. M. Hewitt, Talking About Leaving: Why Undergraduates Leave the Sciences (Westview Press, Boulder, CO, 1997).

[52] H. A. Williquette and D. H. Khaliqi, STEM academic and career identity formation among middle school students, in Educational Research: Theory and Practice 28, 31 (2021), http://www.nrmera.org/wp-content/uploads/ 2017/01/Williquette.and_.Khaliqi.Vol28.Iss2_.2016.pdf.
[53] T. Visintainer, "I think at first glance people would not expect me to be interested in science": Exploring the racialized science experiences of high school students of color, J. Res. Sci. Teach. 57, 393 (2020).

[54] R. Ivie, S. White, and R. Y. Chu, Women's and men's career choices in astronomy and astrophysics, Phys. Rev. Phys. Educ. Res. 12, 020109 (2016).

[55] J. Langford and P. R. Clance, The imposter phenomenon: Recent research findings regarding dynamics, personality and family patterns and their implications for treatment, Psych. Theo. Res. Pract. Train. 30, 495 (1993).

[56] J. S. Eccles, Gender roles and women's achievementrelated decisions, Psychol. Women Q. 11, 135 (1987).

[57] J. S. Eccles, J. E. Jacobs, and R. D. Harold, Gender role stereotypes, expectancy effects, and parents' socialization of gender differences, J. Soc. Issues 46, 183 (1990).

[58] E. A. Gunderson, G. Ramirez, S. C. Levine, and S. L. Beilock, The role of parents and teachers in the development of gender-related math attitudes, Sex Roles 66, 153 (2012).

[59] H. R. Tenenbaum and C. Leaper, Parent-child conversations about science: The socialization of gender inequities?, Dev. Psychol. 39, 34 (2003).

[60] A. Wigfield, J. S. Eccles, K. S. Yoon, R. D. Harold, A. J. A. Arbreton, C. Freedman-Doan, and P.C. Blumenfeld, Change in children's competence beliefs and subjective task values across the elementary school years: A 3-year study, J. Educ. Psychol. 89, 451 (1997).

[61] S. J. Correll, Constraints into preferences: Gender, status, and emerging career aspirations, Am. Sociol. Rev. 69, 93 (2004).

[62] P. G. Davies, S. J. Spencer, D. M. Quinn, and R. Gerhardstein, Consuming images: How television commercials that elicit stereotype threat can restrain women academically and professionally, Pers. Soc. Psychol. Bull. 28, 1615 (2002).

[63] B. Ertl, S. Luttenberger, and M. Paechter, The impact of gender stereotypes on the self-concept of female students in STEM subjects with an underrepresentation of females, Front. Psychol. 8, 703 (2017).

[64] C. Schuster and S.E. Martiny, Not feeling good in STEM: Effects of stereotype activation and anticipated affect on women's career aspirations, Sex Roles 76, 40 (2017)

[65] A. Smeding, Women in science, technology, engineering, and mathematics (STEM): An investigation of their implicit gender stereotypes and stereotypes' connectedness to math performance, Sex Roles 67, 617 (2012).

[66] A. Moè, M. Hausmann, and M. Hirnstein, Gender stereotypes and incremental beliefs in STEM and non-STEM students in three countries: relationships with performance in cognitive tasks, Psychol. Res. 85, 554 (2021).

[67] J. Jacobs, Influence of gender stereotypes on parent and child mathematics attitudes, J. Educ. Psychol. 83, 518 (1991).

[68] C. Steele, A threat in the air. How stereotypes shape intellectual identity and performance, Am. Psychol. 52, 613 (1997).

[69] J.-C. Croizet, M. Désert, M. Dutrévis, and J.-P. Leyens, Stereotype threat, social class, gender, and academic 
under-achievement: When our reputation catches up to us and takes over, Soc. Psychol. Educ. 4, 295 (2001).

[70] J. Tiedemann, Parents' gender stereotypes and teachers' beliefs as predictors of children's concept of their mathematical ability in elementary school, J. Educ. Psychol. 92, 144 (2000).

[71] S. Cheryan, V. C. Plaut, P. G. Davies, and C. M. Steele, Ambient belonging: How stereotypical cues impact gender participation in computer science, J. Pers. Soc. Psychol. 97, 1045 (2009).

[72] C. M. Steele, S. J. Spencer, and J. Aronson, Contending with group image: The psychology of stereotype and social identity threat (Academic Press, New York, 2002), pp. 379-440.

[73] J. C. Blickenstaff, Women and science careers: Leaky pipeline or gender filter?, Gender Educ. 17, 369 (2005).

[74] J. L. Cundiff, T. K. Vescio, E. Loken, and L. Lo, Do gender-science stereotypes predict science identification and science career aspirations among undergraduate science majors?, Soc. Psychol. Educ. 16, 541 (2013).

[75] D. M. Young, L. A. Rudman, H. M. Buettner, and M. C. McLean, The influence of female role models on women's implicit science cognitions, Psychol. Women Q. 37, 283 (2013).

[76] Z. Hazari, D. Chari, G. Potvin, and E. Brewe, The context dependence of physics identity: Examining the role of performance/competence, recognition, interest, and sense of belonging for lower and upper female physics undergraduates, J. Res. Sci. Teach. 57, 1583 (2020).

[77] Z. Y. Kalender, E. Marshman, C. D. Schunn, T. J. NokesMalach, and C. Singh, Gendered patterns in the construction of physics identity from motivational factors, Phys. Rev. Phys. Educ. Res. 15, 020119 (2019).

[78] Z. Y. Kalender, E. Marshman, C. D. Schunn, T. J. NokesMalach, and C. Singh, Damage caused by women's lower self-efficacy on physics learning, Phys. Rev. Phys. Educ. Res. 16, 010118 (2020).

[79] A. J. Gonsalves, Exploring how gender figures the identity trajectories of two doctoral students in observational astrophysics, Phys. Rev. Phys. Educ. Res. 14, 010146 (2018).

[80] R. S. Barthelemy, M. McCormick, and C. Henderson, Gender discrimination in physics and astronomy: Graduate student experiences of sexism and gender microaggressions, Phys. Rev. Phys. Educ. Res. 12, 020119 (2016).

[81] D. Tager and G. E. Good, Italian and american masculinities: A comparison of masculine gender role norms, Psychol. Men Masc. 6, 264 (2005).

[82] A. L. Amodeo, C. Esposito, and D. Bacchini, Heterosexist microaggressions, student academic experience and perception of campus climate: Findings from an italian higher education context, PLoS One 15, e0231580 (2020).

[83] P. L. Gardner and P. Tamir, Interest in biology. Part I: A multidimensional construct, J. Res. Sci. Teach. 26, 409 (1989).

[84] C. Morgan, J. D. Isaac, and C. Sansone, The role of interest in understanding the career choices of female and male college students, Sex Roles 44, 295 (2001).
[85] N. Fouad, P. Smith, and K. Zao, Across academic domains: Extensions of the social-cognitive career model, J. Counsel. Psychol. 49, 164 (2002).

[86] R. H. Tai, C. Qi Liu, A. V. Maltese, and X. Fan, Planning early for careers in science, Science 312, 1143 (2006).

[87] U. Schiefele, A. Krapp, and A. Winteler, Interest as a Predictor of Academic Achievement: A Meta-Analysis of Research (Lawrence Erlbaum, Hillsdale, NJ, 1992), pp. 183-212.

[88] M. Windschitl, Interest, Epistemiological Belief, and Intentional Conceptual Change (Lawrence Erlbaum Associates, Hillsdale, NJ, 2003), pp. 173-197.

[89] L. Mason, M. Gava, and A. Boldrin, On warm conceptual change: The interplay of text, epistemological beliefs, and topic interest, J. Educ. Psychol. 100, 291 (2008).

[90] H. Kang, L. C. Scharmann, S. Kang, and T. Noh, Cognitive conflict and situational interest as factors influencing conceptual change, Int. J. Env. Sci. Educ. 5, 383 (2010), http://www.ijese.net/makale_indir/ IJESE_1424_article_582c0312c25d9.pdf.

[91] K. A. Renninger, Interest and identity development in instruction: An inductive model, Educ. Psychol. 44, 105 (2009).

[92] S. Hidi and K. A. Renninger, The four-phase model of interest development, Educ. Psychol. 41, 111 (2006).

[93] P. Haussler, L. Hoffman, R. Langeheine, d. J. Rost, and K. Sievers, A typology of students' interest in physics and the distribution of gender and age within each type, Int. J. Sci. Educ. 20, 223 (1998).

[94] M. Zeilik, C. Schau, N. Mattern, S. Hall, K. W. Teague, and W. Bisard, Conceptual astronomy: A novel model for teaching post-secondary science courses, Am. J. Phys. 65, 987 (1997).

[95] A. Kareva, S. Miller, A. Foster, and C. R. James, A comparison of astronomy/science attitudes among students and secondary teachers, in American Astronomical Society Meeting Abstracts 223 (American Astronomical Society, Cambridge MA, 2014).

[96] B. Bektasli, The effect of media on preservice science teachers' attitudes toward astronomy and achievement in astronomy class, Turk. Online J. Educ. Technol. 12, 139 (2013), http://www.tojet.net/articles/v12i1/12115.pdf.

[97] S. Ucar and T. Demircioglu, Changes in preservice teacher attitudes toward astronomy within a semesterlong astronomy instruction and four-year-long teacher training programme, J. Sci. Educ. Technol. 20, 65 (2011).

[98] J. M. Bailey, D. Lombardi, J. R. Cordova, and G. M. Sinatra, Meeting students halfway: Increasing selfefficacy and promoting knowledge change in astronomy, Phys. Rev. Phys. Educ. Res. 13, 020140 (2017).

[99] M. Krstovic, L. Brown, M. Chacko, and B. Trinh, Grade 9 astronomy study: Interests of boys and girls studying astronomy at Fletcher's Meadow secondary school, Astron. Educ. Rev. 7, 18 (2008).

[100] J. Lavonen, R. Byman, K. Juuti, V. Meisalo, and A. Uitto, Pupil interest in physics: A survey in Finland, Nord. Stud. Sci. Educ. 2, 72 (2005).

[101] R. M. Ryan and E. L. Deci, Intrinsic and extrinsic motivations: Classic definitions and new directions, Contemp. Educ. Psychol. 25, 54 (2000). 
[102] A. Wigfield and J. S. Eccles, Expectancy-value theory of achievement motivation, Contemp. Educ. Psychol. 25, 68 (2000).

[103] J. Eccles, T. Adler, R. Futterman, S. Goff, C. Kaczala, J. Meece, and C. Midgley, Expectancies, values, and academic behaviours, in Achievement and Achievement Motivation, edited by J. T. Spence (W. H. Freeman, San Francisco, CA, 1983), pp. 75-146.

[104] J. Eccles, B. Barber, and D. Jozefowicz, Linking Gender to Education, Occupation, and Recreational Choices: Applying the Eccles et al. Model of Achievement-Related Choices, edited by W. B. Swann, Jr., J. H. Langlois, and L. A. Gilbert (American Psychological Association, Washington, DC, 1999), pp. 153-192, https://doi.org/ 10.1037/10277-007.

[105] M. V. Bøe and E. K. Henriksen, Love it or leave it: Norwegian students' motivations and expectations for postcompulsory physics, Sci. Educ. 97, 550 (2013).

[106] J. S. Eccles and R. D. Harold, Gender differences in sport involvement: Applying the Eccles' expectancy-value model, J. Appl. Spectrosc. 3, 7 (1991).

[107] K. A. Updegraff, J. S. Eccles, B. L. Barber, and K. M. O'Brien, Course enrollment as self-regulatory behavior: Who takes optional high school math courses?, Learning Indiv. Diff. 8, 239 (1996), Special issue: A symposium on self-regulated learning.

[108] A. Wigfield, Expectancy-value theory of achievement motivation: A developmental perspective, Educ. Psychol. Rev. 6, 49 (1994).

[109] P. Xiang, A. Chen, and A. Bruene, Interactive impact of intrinsic motivators and extrinsic rewards on behavior and motivation outcomes, J. Teaching Phys. Educ. 24, 179 (2005).

[110] M. Bong, Academic motivation in self-efficacy, task value, achievement goal orientations, and attributional beliefs, J. Educ. Res. 97, 287 (2004).

[111] J. Cole, D. Bergin, and T. Whittaker, Predicting student achievement for low stakes tests with effort and task value, Contemp. Educ. Psychol. 33, 609 (2008).

[112] A. Durik, M. Vida, and J. Eccles, Task values and ability beliefs as predictors of high school literacy choices: A developmental analysis, J. Educ. Psychol. 98, 382 (2006).

[113] C. Hulleman, A. Durik, S. Schweigert, and J. Harackiewicz, Task values, achievement goals, and interest: An integrative analysis, J. Educ. Psychol. 100, 398 (2008)

[114] D. Mac Iver, D. Stipek, and D. Daniels, Explaining within semester changes in student effort in junior high school and senior high school courses, J. Educ. Psychol. 83, 201 (1991).

[115] J. Simons, S. Dewitte, and W. Lens, The role of different types of instrumentality in motivation, study strategies, and performance: Know why you learn, so you'll know what you learn!, Br. J. Educ. Psychol. 74, 343 (2004).

[116] J. Harackiewicz, A. Durik, K. Barron, L. LinnenbrinkGarcia, and J. Tauer, The role of achievement goals in the development of interest: Reciprocal relations between achievement goals, interest, and performance, J. Educ. Psychol. 100, 105 (2008).
[117] C. Hulleman, O. Godes, B. Hendricks, and J. Harackiewicz, Enhancing interest and performance with a utility value intervention, J. Educ. Psychol. 102, 880 (2010).

[118] R. S. Barthelemy and A. V. Knaub, Gendered motivations and aspirations of university physics students in Finland, Phys. Rev. Phys. Educ. Res. 16, 010133 (2020).

[119] R. M. Lock, Z. Hazari, and G. Potvin, Impact of out-ofclass science and engineering activities on physics identity and career intentions, Phys. Rev. Phys. Educ. Res. 15, 020137 (2019).

[120] A. Rachmatullah and M. Ha, Examining high-school students' overconfidence bias in biology exam: A focus on the effects of country and gender, Int. J. Sci. Educ. 41, 652 (2019).

[121] J. Yates, J.-W. Lee, H. Shinotsuka, A. L. Patalano, and W. R. Sieck, Cross-cultural variations in probability judgment accuracy: Beyond general knowledge overconfidence?, Organ. Behav. Human Decision Processes 74, 89 (1998).

[122] M. V. J. Veenman, B. H. A. M. Van Hout-Wolters, and P. Afflerbach, Metacognition and learning: Conceptual and methodological considerations, Metacogn. Learn. 1, 3 (2006).

[123] N. Destan and C. M. Roebers, What are the metacognitive costs of young children's overconfidence?, Metacogn. Learn. 10, 347 (2015).

[124] J. Viljaranta, A. Tolvanen, K. Aunola, and J.-E. Nurmi, The developmental dynamics between interest, selfconcept of ability, and academic performance, Scand. J. Educ. Res. 58, 734 (2014).

[125] E. Regan and J. DeWitt, Attitudes, interest and factors influencing STEM enrolment behavior: An overview of relevant literature, in Understanding Student Participation and Choice in Science and Technology Education (Springer, New York, 2015), pp. 43-51.

[126] T. Bouffard and S. Narciss, Benefits and risks of positive biases in self-evaluation of academic competence: Introduction, Int. J. Educ. Res. 50, 205 (2011).

[127] L. Stankov, Noncognitive predictors of intelligence and academic achievement: An important role of confidence, Personal. Individ. Differ. 55, 727 (2013).

[128] B. Sreenivasulu and R. Subramaniam, Exploring undergraduates' understanding of transition metals chemistry with the use of cognitive and confidence measures, Res. Sci. Educ. 44, 801 (2014).

[129] P. P. Chen, Exploring the accuracy and predictability of the self-efficacy beliefs of seventh-grade mathematics students, Learn. Individ. Differ. 14, 77 (2003).

[130] J. Möller and B. Pohlmann, Achievement differences and self-concept differences: Stronger associations for above or below average students?, Br. J. Educ. Psychol. 80, 435 (2010).

[131] M. M. Chiu and R. M. Klassen, Relations of mathematics self-concept and its calibration with mathematics achievement: Cultural differences among fifteen-year-old in 34 countries, Learn. Instr. 20, 2 (2010).

[132] W. Wood and A.H. Eagly, Chapter two-Biosocial construction of sex differences and similarities in behavior (Academic Press, New York, 2012), pp. 55-123. 
[133] J. Keller and L. Molix, When women can't do math: The interplay of self-construal, group identification, and stereotypic performance standards, J. Exp. Soc. Psychol. 44, 437 (2008).

[134] G. Pallier, Gender differences in the self-assessment of accuracy on cognitive tasks, Sex Roles 48, 265 (2003).

[135] S. Hasan, D. Bagayoko, and E. Kelley, Misconceptions and the certainty of response index, Phys. Educ. 34, 294 (1999).

[136] M. Planinic, W. Boone, R. Krsnik, and M. Beilfuss, Exploring alternative conceptions from newtonian dynamics and simple DC circuits: Links between item difficulty and item confidence, J. Res. Sci. Teach. 43, 150 (2006).

[137] B. A. Lindsey and M. L. Nagel, Do students know what they know? Exploring the accuracy of students' selfassessments, Phys. Rev. ST Phys. Educ. Res. 11, 020103 (2015).

[138] I. Testa, A. Colantonio, S. Galano, I. Marzoli, F. Trani, and U. Scotti di Uccio, Effects of instruction on students' overconfidence in introductory quantum mechanics, Phys. Rev. Phys. Educ. Res. 16, 010143 (2020).

[139] I. Caleon and R. Subramaniam, Development and application of a three-tier diagnostic test to assess secondary students' understanding of waves, Int. J. Sci. Educ. 32, 939 (2010).

[140] S. Aretz, A. Borowski, and S. Schmeling, The role of confidence in ordered multiple-choice items about the universe's expansion, in Proceedings of the Annual meeting of Society for Didactics of Chemistry and Physics (Gesellschaft für Didaktik der Chemie und Physik, Essen (GER), 2017), https://gdcp-ev.de/wp-content/ tb2018/TB2018_90_Aretz.pdf.

[141] A.-M. Bliuc, R. A. Ellis, P. Goodyear, and D. M. Hendres, Understanding student learning in context: Relationships between university students' social identity, approaches to learning, and academic performance, Eur. J. Psychol. Educ. 26, 417 (2011).

[142] M. J. Platow, K. I. Mavor, and D. M. Grace, On the role of discipline-related self-concept in deep and surface approaches to learning among university students, Instr. Sci. 41, 271 (2013).

[143] D. Hestenes, M. Wells, and G. Swackhamer, Force Concept Inventory, Phys. Teach. 30, 141 (1992).

[144] J. M. Bailey and T. Slater, A review of astronomy education research, Astron. Educ. Rev. 2, 20 (2003).

[145] A. Lelliott and M. Rollnick, Big ideas: A review of astronomy education research 1974-2008, Int. J. Sci. Educ. 32, 1771 (2010).

[146] I. Testa, S. Galano, S. Leccia, and E. Puddu, Development and validation of a learning progression for change of seasons, solar and lunar eclipses, and moon phases, Phys. Rev. ST Phys. Educ. Res. 11, 020102 (2015).

[147] J. D. Plummer, C. Palma, K. Rubin, A. Flarend, Y. S. Ong, C. Ghent, T. Gleason, S. McDonald, B. Botzer, and T. Furman, Evaluating a learning progression for the solar system: Progress along gravity and dynamical properties dimensions, Sci. Educ. 104, 530 (2020).
[148] B. M. Capobianco, B. F. French, and H. A. Diefes-Dux, Engineering identity development among pre-adolescent learners, J. Eng. Educ. 101, 698 (2012).

[149] A. Godwin, G. Potvin, Z. Hazari, and R. Lock, Understanding engineering identity through structural equation modeling, in Proceedings of the 2013 IEEE Frontiers in Education Conference (FIE) (IEEE Education Society, Oklahoma, 2013), pp. 50-56, https://doi.org/10.1109/ FIE.2013.6684787.

[150] Italian ministry of education, Curriculum guidelines of Italian primary school (2012).

[151] Italian ministry of education, Curriculum guidelines of Italian middle school (2012).

[152] See Supplemental Material at http://link.aps.org/ supplemental/10.1103/PhysRevPhysEducRes.17.010139 for part A: a report of the two forms of conceptual knowledge questionnaire, and part B: a report of descriptive statistics of the interest, utility value, and identity items and the breakdown of knowledge and confidence responses for seasonal changes, Moon phases, and eclipses.

[153] J. Schreiber, A. Nora, F. Stage, E. Barlow, and J. King, Reporting structural equation modeling and confirmatory factor analysis results: A review, J. Educ. Res. 99, 323 (2006).

[154] J. Hair, M. Sarstedt, L. Hopkins, and V. Kuppelwieser, Partial least squares structural equation modeling (PLS-SEM): An emerging tool for business research, Eur. Bus. Rev. 26, 106 (2014).

[155] C. Barbaranelli and S. Ingoglia, I modelli di equazioni strutturali. Temi e prospettive, in Strumenti e metodi per le scienze sociali (LED Edizioni Universitarie, Milano, 2013).

[156] A. Godwin, G. Potvin, Z. Hazari, and R. Lock, Identity, critical agency, and engineering: An affective model for predicting engineering as a career choice, J. Eng. Educ. 105, 312 (2016)

[157] T. Brown, Confirmatory Factor Analysis for Applied Research (Guilford Press, New York, London, 2006).

[158] E. Oppermann, J. Vinni-Laakso, K. Juuti, A. Loukomies, and K. Salmela-Aro, Elementary school students' motivational profiles across finnish language, mathematics and science: Longitudinal trajectories, gender differences and STEM aspirations, Contemp. Educ. Psychol. 64, 101927 (2021).

[159] Y. Zhu, How Chinese students' scientific competencies are influenced by their attitudes?, Int. J. Sci. Educ. 41, 2094 (2019).

[160] J. Hutchinson and K. Bentley, STEM subjects and jobs: a longitudinal perspective of attitudes among key stage 3 students, 2008-2010, http://hdl.handle.net/10545/197191 (2011).

[161] T. Lyons, The puzzle of falling enrolments in physics and chemistry courses: Putting some pieces together, Res. Sci. Educ. 36, 285 (2006).

[162] J. Bennett and S. Hogarth, Would you want to talk to a scientist at a party? High school students' attitudes to school science and to science, Int. J. Sci. Educ. 31, 1975 (2009). 
[163] J. Craig and D. Ayres, Does primary science affect girls' and boys' interest in secondary science?, Sch. Sci. Rev. 69, 417 (1988).

[164] P. Häussler, Measuring students' interest in physicsdesign and results of a cross-sectional study in the Federal Republic of Germany, Int. J. Sci. Educ. 9, 79 (1987).

[165] J. L. M. Wilkins, Mathematics and science self-concept: An international investigation, J. Exp. Educ. 72, 331 (2004).

[166] R. Trumper, Factors affecting junior high school students' interest in physics, J. Sci. Educ. Technol. 15, 47 (2006).

[167] A. V. Maltese and R. H. Tai, Eyeballs in the fridge: Sources of early interest in science, Int. J. Sci. Educ. 32, 669 (2010).

[168] G. C. Marchand and G. Taasoobshirazi, Stereotype threat and women's performance in physics, Int. J. Sci. Educ. 35, 3050 (2013).
[169] M. Appel and N. Kronberger, Stereotypes and the achievement gap: Stereotype threat prior to test taking, Educ. Psychol. Rev. 24, 609 (2012).

[170] C. M. Ganley, L. A. Mingle, A. M. Ryan, K. Ryan, M. Vasilyeva, and M. Perry, An examination of stereotype threat effects on girls' mathematics performance, Dev. Psychol. 49, 1886 (2013).

[171] A. Maries and C. Singh, Stereotype threat? Effects of inquiring about test takers' gender on conceptual test performance in physics, AIP Conf. Proc. 1697, 120008 (2015).

[172] A. Maries, N. I. Karim, and C. Singh, Is agreeing with a gender stereotype correlated with the performance of female students in introductory physics?, Phys. Rev. Phys. Educ. Res. 14, 020119 (2018).

[173] L. J. Stricker and W. C. Ward, Stereotype threat, inquiring about test takers' ethnicity and gender, and standardized test performance, J. Appl. Soc. Psychol. 34, 665 (2004). 